\title{
¿Cómo han vivido los adultos mayores la pandemia COVID-19?*
}

\author{
[Artículos]
}

Joan Tahull Fort ${ }^{* *}$

Fecha de entrega: 14 de marzo de 2021

Fecha de evaluación: 20 de mayo de 2021

Fecha de aprobación: 08 de junio de 2021

Citar como:

Tahull Fort, J. (2021). ¿Cómo han vivido los adultos mayores la pandemia COVID19? Cuadernos de Filosofía Latinoamericana, 42(125).

https://doi.org/10.15332/25005375.6454

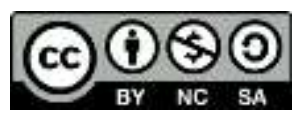

\section{Resumen}

El Gobierno español declaró el estado de alarma el 14 de marzo de 2020 en todo el territorio ante el avance descontrolado de la COVID-19. Se obligó a la población española a un confinamiento estricto y progresivamente se fueron suavizando las restricciones y se entró en la nueva normalidad. Durante meses hubo importantes limitaciones para evitar las interacciones sociales presenciales y los contagios.

Seguramente el colectivo social que más ha sufrido la pandemia y las restricciones impuestas fue el de los adultos mayores. En la investigación se presentan datos cuantitativos oficiales y entrevistas a personas

\footnotetext{
* Este artículo es resultado de las reflexiones e investigaciones personales que ha realizado el autor en torno a la situación imprevista generada por la pandemia del Covid-19. ** Doctor en Sociología por la Universidad de Lleida. Licenciado en Filosofía y también en Antropología Social y Cultural. Diplomado en Trabajo Social. Profesor asociado en la Universidad de Lleida en el Departamento de Sociología y Geografía. Profesor de Formación Profesional, actualmente ejerce en el Instituto de Ciencias de la Educación de la Universidad de Lleida. Correo electrónico: joan.tahull@udl.cat; ORCID: https://orcid.org/0000-0002-4791-1704
} 
conocedoras de la temática. El confinamiento y las restricciones posteriores tuvieron un impacto desigual; muchos adultos mayores han padecido sus consecuencias en soledad y el anonimato. Todavía faltan estudios para conocer en profundidad sus vivencias, opiniones, reflexiones y posibles malestares vividos y sentidos durante la pandemia.

Palabras clave: COVID-19, malestar, pandemia, tercera edad y vejez.

\section{How Have Older Adults Experienced the COVID- 19 Pandemic?}

\section{Abstract}

On March 14, 2020, the Spanish Government declared a state of alarm throughout the country in the face of the uncontrolled spread of COVID19. The Spanish population was forced into strict confinement and, over time, the restrictions were gradually eased and the country started a new normality. For months, there were different measures to avoid face-toface social interactions and infection. Certainly, the social group that suffered most from the pandemic and the restrictions imposed was the elderly. The research presents official quantitative data and interviews with people knowledgeable about the subject. Confinement and subsequent restrictions had an uneven impact; many older adults have suffered the consequences in loneliness and anonymity. There is still a lack of studies to know in-depth their experiences, opinions, reflections, and possible discomforts experienced during the pandemic.

Keywords: COVID-19, malaise, pandemic, old age, aging.

\section{Introducción}

El 14 de marzo de 2020, el Gobierno de España declaró oficialmente el estado de alarma en todo el territorio español (Real Decreto 463/2020, de 14 de marzo) ante el avance descontrolado de la COVID-19. Se cerraron las actividades no esenciales y se decretó el confinamiento obligatorio de la 
población española a sus domicilios. El 28 de abril del mismo año, el Gobierno de España anunció el Plan de Desconfinamiento, mediante el cual se reducían algunas restricciones a la población. El 21 de junio se entró en la nueva normalidad. Las limitaciones a la vida social se flexibilizaron, siendo todavía importantes. El confinamiento y los meses siguientes fueron vividos y sentidos de forma diferente por los diversos colectivos sociales: edad, género, localidad de residencia, posibilidades económicas, competencias digitales...

En la investigación, se presenta un análisis y una reflexión de la pandemia por la COVID-19 (confinamiento obligatorio y posterior desescalada) y de la limitación de la vida social de las personas adultas mayores. Se constata mediante datos cuantitativos y cualitativos cómo vivieron y se sintieron, así como algunas características de las tipologías familiares y posibilidades de uso y manejo de las tecnologías digitales de la comunicación.

Tradicionalmente, la vejez es un periodo de la vida ampliamente estudiado por las ciencias sociales. Durante estos meses se han analizado las consecuencias de la pandemia en diferentes colectivos, siendo escasamente tratadas sus consecuencias en la tercera edad. Se han realizado algunos estudios destacando los estereotipos edadistas, sobre cómo se legitimaban decisiones políticas, conductas y afirmaciones contrarias a las personas mayores, por estar en los últimos años de sus vidas y justificando recursos y esfuerzos hacia otros colectivos. Esta discriminación también se observa en la escasez de estudios sobre las consecuencias de la pandemia en los mayores para mostrar y manifestar sus vivencias, reflexiones y opiniones. El presente estudio pretende llenar humildemente un vacío en las investigaciones de las consecuencias de la pandemia en la vejez y prioritariamente dar luz a algunas opiniones y reflexiones significativas manifestadas por adultos mayores. 


\section{Fundamentos teóricos}

En los últimos años, en las sociedades avanzadas se está produciendo un proceso de constante individualización, que se manifiesta en diferentes ámbitos sociales, incluido el aumento constante de personas mayores viviendo solas, principalmente mujeres por su mayor esperanza de vida (Arruebarrena y Sánchez, 2020; Tahull, 2019). En la actualidad, la vejez no es un periodo corto, próximo a la muerte, sino que para muchos es una etapa larga, siendo en algunos casos la más extensa; tampoco hay vulnerabilidad, vislumbrando la muerte en el horizonte (solamente al final); para muchos, la vejez es la entrada a un periodo fructífero y estimulante (Klein, 2015).

La Organización Mundial de la Salud (OMS) en 2001 defendió un cambio de paradigma del envejecimiento, de una etapa pasiva y triste a una activa y excitante; animó a todos los países a implementar políticas para favorecer un envejecimiento activo, para mejorar la calidad de vida. La vejez debía ser vivida de forma más activa, independiente, dinámica y participativa. Según Fuentes y Osorio (2020), la tercera edad no está integrada por un grupo homogéneo: las condiciones sociales, económicas, culturales y educativas condicionan sus posibilidades; además, tiene influencia la salud, el grupo de amigos (relaciones sociales óptimas), la autonomía funcional, la vitalidad... (Parra-Rizo, 2017).

Para Arias y Polizzi (2011), las relaciones sociales presenciales generan bienestar en las personas mayores; los vínculos de amistad y los contactos familiares mejoran la salud y favorecen la longevidad. Para Waite y Gallagher (2000), en la vejez la familia (especialmente pareja e hijos) es el principal apoyo. Los adultos mayores se sienten más satisfechos con sus vidas y se autoperciben más sanos en relación con la cantidad y calidad de sus relaciones sociales presenciales (Cable et al., 2013). Las personas solas 
se sienten incomprendidas o rechazadas; dudan de sus habilidades sociales para tener relaciones sociales óptimas. La soledad no deseada es desagradable, estresante y genera ansiedad. El aislamiento genera malestar al no tener a un semejante para dialogar, compartir, etc. (Bermejo, 2016; Gajardo, 2015; Golden et al., 2009). El apoyo social implica afecto y ayuda emocional (sentirse querido, intimidad, confianza y disponibilidad), ayuda instrumental (conocimientos y consejos) y afirmación personal (Leturia et al., 2001).

La pandemia ha tenido consecuencias en todos los ámbitos sociales y en todas las edades con distintas intensidades. Según Deusdad (2020), los estados no estaban preparados para hacer frente a esta emergencia sanitaria, social y económica; han improvisado e implementado políticas que después han sido equivocadas. Para Fontana (2020), las personas mayores han sido los más afectados y han tenido mayor riesgo de morir. Habiendo diferencias en la incidencia por aspectos económicos, geográficos, sociales, familiares, etc. Ayalon et al. (2020) alertan del aumento del edadismo y de conductas discriminatorias hacia la tercera edad durante la pandemia. Según Vega et al. (2020) y Fuentes y Osorio (2020), se deben tener en cuenta elementos sanitarios y sociales, como enfermedades, soledad, etc. Para Zhang et al. (2020), el estrés ha aumentado en las personas mayores y se requieren acciones específicas para tratarlo; destacan los peligros de la depresión, su no tratamiento y cronificación. Según Khan et al. (2017), los adultos mayores tienen menos capacidades de adaptación biológica y psicológica a los cambios. Durante la pandemia se han limitado las relaciones sociales presenciales y muchas personas (especialmente en la tercera edad) no tienen los dispositivos ni las competencias digitales necesarias para comunicarse. Muchas personas mayores viven solas en un contexto de normalidad; en circunstancias extraordinarias, como la pandemia, todavía han reducido más las 
interacciones, siendo la soledad y el aislamiento el denominador común (Quiroga, 2020).

Para Galeano et al. (2020), los ancianos han estado confinados en sus hogares durante días, meses, con pocas interacciones con el exterior. El cuidado, la empatía y la solidaridad mejora su estado emocional. La prohibición de visitar a los ancianos y la separación intergeneracional se valora socialmente una buena acción, por prevenir el contagio y la muerte; aunque estas conductas debilitan la cadena intergeneracional, los vínculos de cuidado y las redes de apoyo, aumenta la marginación, la soledad y el aislamiento. La tercera edad tiene muchas dificultades para compensar estas limitaciones y usar las tecnologías digitales de comunicación. La brecha digital en los mayores es más intensa; tienen más problemas para comunicarse con familiares, amigos, etc. (Arruebarrena y Sánchez, 2020). Para Ruiz Osorio (2020), se han producido situaciones disruptivas por la inquietante presencia de la muerte y la imposibilidad de realizar los necesarios rituales de duelo socialmente establecidos. Di Nola (2007) explica que la muerte impone una experiencia de desorden y disgregación de la realidad que afecta al individuo y al grupo sobreviviente. Los rituales son necesarios para restablecer el orden, la seguridad y la confianza en la estructura social y cultural. Santillán (2020) dice que las personas mayores durante este periodo han perdido a seres queridos o próximos (familiares, amigos o allegados). Según Fuentes y Ruiz Osorio (2020), la pandemia genera una bifurcación de biografías. Un cambio rápido, imprevisible y descontrolado de las vidas de las personas, especialmente en la vejez, puede ser irreversible. Estas transformaciones han sucedido con el miedo, la angustia y la incertidumbre incrustados en la mente (Albós et al., 2020). Durante estos meses ha habido una sedentarización y reclusión de la población en los hogares. Las personas, especialmente los 
mayores, han vivido con la muerte muy presente y sin comprender claramente los hechos que estaban sucediendo (Klein, 2020).

Para Han (2020), la pandemia aísla a los individuos y profundiza el individualismo de las sociedades posmodernas. Cada persona se preocupa principalmente por su supervivencia. La solidaridad consiste en mantener las distancias y evitar el contacto con los semejantes, alejando el ideal de construir sociedades más justas y pacíficas. En estas circunstancias, algunos gobiernos podrían seguir políticas eugenésicas; podrían implementar acciones públicas para rejuvenecer las naciones abandonando a su suerte a las poblaciones más vulnerables (Zizek, 2020). En algunos casos, la democracia podría estar en peligro por el surgimiento de gobiernos autoritarios (Harari, 2020).

\section{Metodología}

Para realizar el artículo, se ha utilizado información cuantitativa de la Encuesta de Condiciones de Vida (ECV) del Instituto Nacional de Estadística (INE). Se han presentado datos de la población residente según sexo, grupo de edad y situación del hogar, así como uso de Internet por características demográficas y frecuencia de uso. Se ha complementado con información cualitativa, para completar y describir situaciones específicas significativas. Se han realizado 20 entrevistas a personas mayores de 65 años: 10 residentes en ciudades (Barcelona y Lleida) y 10 domiciliados en un entorno rural, en dos provincias, también en Barcelona y Lleida. Se han buscado informantes que pudieran ofrecer una mirada concreta, específica y significativa. Todos son catalanes ${ }^{1}$. Los criterios para ser entrevistados han sido: rural/urbano, mayores de 65 años,

\footnotetext{
${ }^{1}$ Cataluña es una comunidad autónoma española, considerada nacionalidad histórica. Situada en el norteste de la península Ibérica que limita al norte con al norte con Francia y Andorra, al este con el Mar Mediterráneo, al sur con la comunidad valenciana y al oeste con Aragón.
} 
hombre/mujer ( 8 hombres y 12 mujeres), variedad de edades, clases sociales diferentes. Algunas viven solas y otros con sus cónyuges. Todos son anónimos aunque son conocedores de la temática estudiada. Los entrevistados no son una muestra representativa de la población española ni catalana.

Se ha contactado con los informantes por amistades o conocidos mediante teléfono y pocos por correo electrónico. Una vez confirmada la posibilidad de realizar la entrevista, nos hemos desplazado a su localidad y se ha realizado en su casa principalmente o en un lugar público. Las entrevistas han sido abiertas y se han grabado, con su consentimiento informado. Se han transcrito solamente las partes más relevantes. Han expresado diferentes situaciones sociales, unas con una perspectiva urbana y otros, rural. Todos los entrevistados han participado y explicado extensamente los temas planteados. Quizás la situación que han vividos estos meses y la escasez de relaciones sociales ha posibilitado que la colaboración fuese más generosa y detallada. Se les ha informado que se mantendría su nombre en anonimato y la información sería solamente utilizada para el estudio.

Todas las investigaciones sociales presentan la limitación de la subjetividad, para acercarse a analizar y describir la compleja e inabarcable realidad social. Se han priorizado aquellas reflexiones y vivencias más representativas, repetidas y reiteradas; también aquellas cuyo encaje en el relato fuese más adecuado. Se ha intentado contrastar, comparar y valorar todos los datos para presentar aquellas ideas y opiniones más significativas (Ander Egg, 2000). En todo caso, los datos presentados son relevantes y significativos para construir y dar coherencia y solidez al relato. 
La información ha sido suficiente, aunque siempre limitada y susceptible de futuras mejoras y precisiones. Con una muestra más extensa, se hubiese afinado más los resultados y conclusiones. La triangulación ha sido un elemento fundamental para construir el relato, aunque la mayoría de la información no aparece en los resultados (también muy importante para contrastarlos), ha permitido tener una visión global, específica y profunda del tema tratado.

\section{Resultados}

En este apartado, se presentan datos cuantitativos y cualitativos de las personas mayores de 60 años y más, de ambos sexos, su situación en el hogar, y la frecuencia de uso de Internet en personas de 75 años y más. Los datos son de la ECV del INE del 2019. En el segundo bloque, se presentan reflexiones de personas de 60 años o más para contextualizar y situar los datos y tener una perspectiva de sus vivencias durante el confinamiento y la nueva normalidad.

En la tabla 1 se muestra información de la población española de 60 años y más, de ambos sexos, y su situación en el hogar durante el 2019:

Tabla 1. Población de 60 años y más, ambos sexos y situación del hogar durante el 2019

\begin{tabular}{|c|c|c|c|c|c|c|}
\hline & \multicolumn{6}{|c|}{ Ambos sexos } \\
\hline & 60-64 años & 65-69 años & $\begin{array}{l}\text { 70-74 } \\
\text { años }\end{array}$ & $\begin{array}{l}75-79 \\
\text { años }\end{array}$ & $\begin{array}{l}80-84 \\
\text { años }\end{array}$ & $\begin{array}{l}85 \text { años o } \\
\text { más }\end{array}$ \\
\hline $\begin{array}{c}\text { Total (situación en el } \\
\text { hogar) }\end{array}$ & 2847,7 & 2387,1 & 2193,1 & 1667,2 & 1269,3 & 1316,8 \\
\hline $\begin{array}{l}\text { Personas que conviven } \\
\text { con su cónyuge }\end{array}$ & 1933,2 & 1658,3 & 1500,2 & 1053,5 & 627,8 & 415,7 \\
\hline $\begin{array}{c}\text { Personas que son } \\
\text { parte de una pareja de } \\
\text { hecho }\end{array}$ & 94,6 & 68,9 & 35,9 & 19,9 & 10,9 & 5,5 \\
\hline $\begin{array}{l}\text { Personas que no } \\
\text { conviven en pareja }\end{array}$ & 180,3 & 140,4 & 117,0 & 131,7 & 128,0 & 204,5 \\
\hline
\end{tabular}

Cuadernos de Filosofía Latinoamericana ISSN: 0120-8462 | e-ISSN: 2500-5375 | DOI: https://doi.org/10.15332/25005375 


\begin{tabular}{|c|c|c|c|c|c|c|}
\hline & \multicolumn{6}{|c|}{ Ambos sexos } \\
\hline & 60-64 años & 65-69 años & $\begin{array}{l}\text { 70-74 } \\
\text { años }\end{array}$ & $\begin{array}{l}75-79 \\
\text { años }\end{array}$ & $\begin{array}{l}80-84 \\
\text { años }\end{array}$ & $\begin{array}{l}85 \text { años o } \\
\text { más }\end{array}$ \\
\hline \multicolumn{7}{|l|}{$\begin{array}{l}\text { pero forman núcleo } \\
\text { con algún hijo }\end{array}$} \\
\hline $\begin{array}{l}\text { Hijos/Hijas no del } \\
\text { padre o madre solos }\end{array}$ & 10,1 & 1,9 & 0,3 & .. & .. & .. \\
\hline $\begin{array}{l}\text { Hijos/Hijas del padre o } \\
\text { madre solos }\end{array}$ & 65,2 & 22,6 & 9,0 & 1,2 & .. & .. \\
\hline $\begin{array}{c}\text { Personas que viven } \\
\text { solas }\end{array}$ & 405,6 & 371,1 & 412,6 & 370,5 & 393,9 & 461,1 \\
\hline
\end{tabular}

Nota: Unidades: miles de personas.

Fuente: Instituto Nacional de Estadística (2021).

Se presenta información de la población de 60 años y más y las diferentes tipologías familiares. En la columna de 6o-64 años, son 2847,7 miles de personas en total, progresivamente, en edades superiores van disminuyendo. En la columna de 70-74 años son 2193,1 miles de personas y 85 años o más son 1316,8 miles de personas. En referencia a personas que conviven con su cónyuge, en el periodo de 6o-64 años son 1933,2 miles de personas (la opción mayoritaria); en cambio, en el periodo de 85 años o más, solamente hay 415,7 miles de personas. Ha habido un descenso brusco. En referencia a las personas que viven solas, en los 60-65 años son 405,6 miles de personas, lejos de la opción mayoritaria (personas que conviven con su cónyuge), es la segunda posibilidad más numerosa. Por el contrario, de 85 años o más 461,1 miles de personas viven solas, es la opción mayoritaria en esta etapa de la vida. Los datos muestran un número significativo de personas mayores de 60 años o más que viven solas.

En la tabla 2 se muestra información de la población española de 60 años y más, específicamente varones y su situación en el hogar durante el 2019: 
Tabla 2. Población de 60 años y más, hombres y situación del hogar durante el 2019

\begin{tabular}{|c|c|c|c|c|c|c|}
\hline & \multicolumn{6}{|c|}{ Hombre } \\
\hline & $\begin{array}{l}\text { 60-64 } \\
\text { años }\end{array}$ & $\begin{array}{l}\text { 65-69 } \\
\text { años }\end{array}$ & $\begin{array}{l}\text { 70-74 } \\
\text { años }\end{array}$ & $\begin{array}{l}\text { 75-79 } \\
\text { años }\end{array}$ & $\begin{array}{l}80-84 \\
\text { años }\end{array}$ & $\begin{array}{l}85 \text { años o } \\
\text { más }\end{array}$ \\
\hline Total (situación en el hogar) & 1380,2 & 1117,7 & 1034,3 & 736,2 & 525,2 & 465,1 \\
\hline $\begin{array}{l}\text { Personas que conviven con su } \\
\text { cónyuge }\end{array}$ & 996,6 & 853,8 & 811,6 & 575,6 & 382,0 & 278,7 \\
\hline $\begin{array}{l}\text { Personas que son parte de una } \\
\text { pareja de hecho }\end{array}$ & 56,6 & 44,8 & 23,2 & 11,1 & 5,4 & 3,8 \\
\hline $\begin{array}{l}\text { Personas que no conviven en } \\
\text { pareja pero forman núcleo con } \\
\text { algún hijo }\end{array}$ & 42,1 & 30,3 & 24,4 & 20,8 & 23,9 & 36,3 \\
\hline $\begin{array}{l}\text { Hijos/Hijas no del padre o } \\
\text { madre solos }\end{array}$ & 5,0 & 0,7 & .. & .. & .. & .. \\
\hline $\begin{array}{l}\text { Hijos/Hijas del padre o madre } \\
\text { solos }\end{array}$ & 34,1 & 10,4 & 2,3 & 0,9 & .. & .. \\
\hline Personas que viven solas & 178,2 & 130,9 & 131,2 & 102,8 & 90,7 & 101,3 \\
\hline
\end{tabular}

Nota: Unidades: miles de personas.

Fuente: Instituto Nacional de Estadística (2021).

En la tabla se presentan datos de la población masculina de 60 años y más y su situación del hogar. En el periodo de 60-64 años, en total son 1380,2 miles de personas, de las cuales 996,6 miles conviven con su cónyuge y 178,2 miles viven solas. En los 70-74 años, en total son 1034,3 miles de personas, de las cuales 811,6 miles conviven con su cónyuge y 131,2 miles están solas; de 85 años o más en total son 465,1 miles de personas, de las cuales 278,7 miles conviven con su cónyuge y 101,3 miles viven solas. En todos los años, los hombres conviven mayoritariamente con su cónyuge, aunque menos en edades avanzadas.

En la tabla 3 se presentan datos de la población femenina de 60 años y más y su situación del hogar durante el 2019. 
Tabla 3. Población de 60 años y más, mujeres y situación del hogar durante el 2019

\begin{tabular}{|c|c|c|c|c|c|c|}
\hline & \multicolumn{6}{|c|}{ Mujer } \\
\hline & $\begin{array}{l}\text { 60-64 } \\
\text { años }\end{array}$ & $\begin{array}{l}\text { 65-69 } \\
\text { años }\end{array}$ & $\begin{array}{l}\text { 70-74 } \\
\text { años }\end{array}$ & $\begin{array}{l}75-79 \\
\text { años }\end{array}$ & $\begin{array}{l}80-84 \\
\text { años }\end{array}$ & $\begin{array}{l}85 \text { años o } \\
\text { más }\end{array}$ \\
\hline Total (situación en el hogar) & 1467,5 & 1269,4 & 1158,9 & 931,0 & 744,1 & 851,7 \\
\hline $\begin{array}{l}\text { Personas que conviven con } \\
\text { su cónyuge }\end{array}$ & 936,5 & 804,5 & 688,6 & 477,9 & 245,8 & 137,0 \\
\hline $\begin{array}{l}\text { Personas que son parte de } \\
\text { una pareja de hecho }\end{array}$ & 38,0 & 24,1 & 12,7 & 8,8 & 5,6 & 1,7 \\
\hline $\begin{array}{l}\text { Personas que no conviven en } \\
\text { pareja pero forman núcleo } \\
\text { con algún hijo }\end{array}$ & 138,2 & 110,0 & 92,7 & 110,9 & 104,0 & 168,2 \\
\hline $\begin{array}{l}\text { Hijos/Hijas no del padre o } \\
\text { madre solos }\end{array}$ & 5,1 & 1,2 & 0,3 & .. & .. & .. \\
\hline $\begin{array}{l}\text { Hijos/Hijas del padre o } \\
\text { madre solos }\end{array}$ & 31,1 & 12,2 & 6,7 & 0,3 & .. & .. \\
\hline Personas que viven solas & 227,4 & 240,2 & 281,4 & 267,7 & 303,3 & 359,9 \\
\hline
\end{tabular}

Nota: Unidades: miles de personas.

Fuente: Instituto Nacional de Estadística (2021).

La tabla muestra las diferentes organizaciones familiares de las mujeres de 60 años o más. Hay 1467,5 miles de mujeres de 60-64 años, de las cuales 936,5 miles conviven con su cónyuge y 227,4 miles viven solas. En la etapa de 80-84 años son en total 744,1 miles de mujeres, de las cuales 245,8 miles conviven con su cónyuge y 303,3 miles viven solas. En este periodo la mayoría viven solas. En los últimos años, de 85 años o más, en total son 851,7 miles, de las cuales 137,0 miles conviven con su cónyuge y 359,9 miles viven solas. Comparando las tablas 2 y 3 , los hombres conviven más con sus cónyuges; en cambio, las mujeres viven más solas y a partir de los 80 años, la mayoría están solas. Muestra también la mayor esperanza de vida de las mujeres respecto los hombres.

En la tabla 4 se presentan diferentes características de uso de Internet y frecuencia de las personas mayores de 75 años y más durante el 2019. 
Tabla 4. Uso de Internet por características demográficas y frecuencia de uso durante el 2019

\begin{tabular}{|c|c|c|c|c|c|c|c|c|}
\hline & Total & $\begin{array}{c}\text { Han } \\
\text { utilizado } \\
\text { Internet } \\
\text { alguna vez }\end{array}$ & $\begin{array}{c}\text { Han } \\
\text { utilizado } \\
\text { Internet en } \\
\text { los últimos } \\
12 \text { meses }\end{array}$ & $\begin{array}{c}\text { Han } \\
\text { utilizado } \\
\text { Internet en } \\
\text { los últimos } \\
3 \text { meses }\end{array}$ & $\begin{array}{c}\text { Han } \\
\text { utilizado } \\
\text { Internet en } \\
\text { el último } \\
\text { mes }\end{array}$ & $\begin{array}{c}\text { Han utilizado } \\
\text { internet } \\
\text { semanalmente (al } \\
\text { menos una vez a la } \\
\text { semana) }\end{array}$ & $\begin{array}{l}\text { Han utilizado } \\
\text { Internet } \\
\text { diariamente (al } \\
\text { menos una vez } \\
\text { al día) }\end{array}$ & $\begin{array}{c}\text { Utilizan } \\
\text { Internet } \\
\text { varias } \\
\text { veces al día }\end{array}$ \\
\hline \multicolumn{9}{|c|}{ Total de personas (75 y más años) } \\
\hline Total Personas & 4243822 & 24,8 & 23,7 & 23,4 & 23,2 & 18,2 & 11,9 & 10,0 \\
\hline Sexo: hombre & 1722224 & 28,8 & 27,7 & 27,2 & 27,0 & 21,4 & 14,4 & 12,0 \\
\hline Sexo: mujer & 2521598 & 22,0 & 21,1 & 20,8 & 20,6 & 16,1 & 10,2 & 8,7 \\
\hline Edad: de 75 a 84 años & 2889305 & 30,7 & 29,6 & 29,2 & 29,0 & 23,0 & 15,4 & 13,0 \\
\hline Edad: de 85 y más años & 1354517 & 12,2 & 11,3 & 11,1 & 11,0 & 8,0 & 4,6 & 3,7 \\
\hline $\begin{array}{l}\text { Hábitat: más de } 100000 \text { habitantes } \\
\text { y capitales de provincia }\end{array}$ & 1861119 & 31,2 & 30,1 & 29,6 & 29,3 & 24,1 & 16,3 & 13,4 \\
\hline $\begin{array}{l}\text { Hábitat: de } 50000 \text { a } 100000 \\
\text { habitantes }\end{array}$ & 427061 & 28,7 & 27,3 & 27,3 & 27,3 & 20,1 & 14,9 & 13,9 \\
\hline $\begin{array}{l}\text { Hábitat: de } 20000 \text { a } 50000 \\
\text { habitantes }\end{array}$ & 538121 & 22,2 & 20,8 & 20,2 & 20,0 & 13,8 & 7,6 & 6,2 \\
\hline $\begin{array}{l}\text { Hábitat: de } 10000 \text { a } 20000 \\
\text { habitantes }\end{array}$ & 456742 & 17,3 & 16,7 & 16,3 & 16,3 & 12,4 & 9,0 & 8,3 \\
\hline $\begin{array}{l}\text { Hábitat: menos de } 10000 \\
\text { habitantes }\end{array}$ & 960778 & 15,5 & 14,9 & 14,8 & 14,7 & 11,1 & 5,9 & 4,8 \\
\hline
\end{tabular}

Nota: Unidades: número de personas (75 años y más).

Fuente: Instituto Nacional de Estadística (2021).

Cuadernos de Filosofía Latinoamericana

ISSN: 0120-8462 | e-ISSN: 2500-5375 | DOI: https://doi.org/10.15332/25005375

Vol. 42 N. ${ }^{\circ} 125$ | julio-diciembre de 2021 
En la tabla 4 se presentan datos sobre el uso de Internet en las personas mayores de 75 años y más, por sexo y lugar de residencia. El total de personas de 75 años o más son 4243 822, de las cuales 1722224 son hombres y 2521598 mujeres. Ellas tienen más esperanza de vida, viven más años que los hombres. En referencia al uso de Internet, el 28,8 \% de los hombres lo han utilizado alguna vez y las mujeres el 22,0 \%. En la pregunta sobre si han utilizado Internet en los últimos 12 meses, los hombres han respondido sí en un 27,7\%, mientras que las mujeres en un $21,1 \%$. En la pregunta sobre el uso de Internet diariamente (al menos una vez al día), los hombres representan el 14,4 \% y las mujeres 10,2 \%, y sobre la utilización de Internet varias veces al día, los hombres representan el 12,0 \% y las mujeres, el 8,7\%. Los hombres de 75 años o más usan más Internet que las mujeres. Resulta también significativa la relación entre el uso de Internet y los habitantes de la localidad de residencia. En ciudades de más de 100 ooo habitantes, el 13,4 \% utiliza Internet varias veces al día; por el contrario, en aquellas localidades menores de 10 ooo habitantes, solamente el 4,8\%. En las ciudades hay más uso de Internet que en el ámbito rural.

En la tabla 5 se presentan datos de la población de 75 años y más, por sexos, del uso de Internet para realizar determinadas actividades, durante el 2020. 
Tabla 5. Servicios de Internet usados, por motivos particulares, en los últimos tres meses por características demográficas 2020

\begin{tabular}{|c|c|c|c|c|c|c|c|}
\hline & $\begin{array}{l}\overline{\widetilde{J}} \\
\text { 。ㅁ }\end{array}$ & 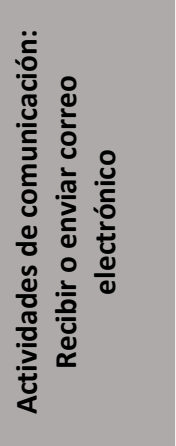 & 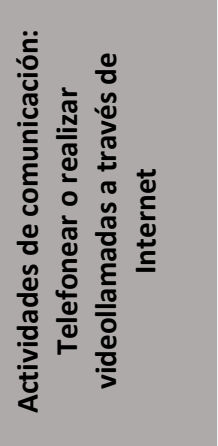 & 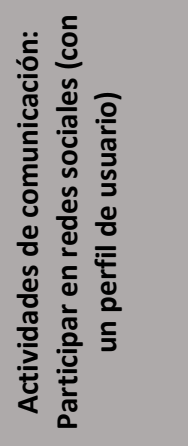 & 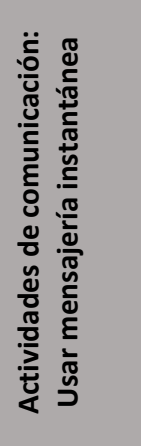 & 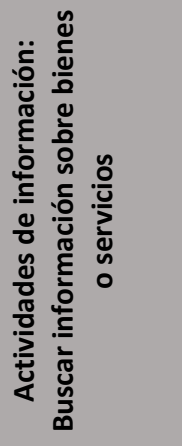 & 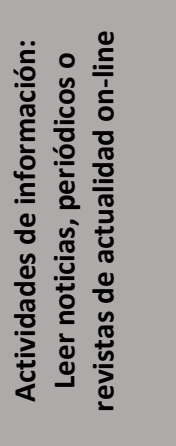 \\
\hline \multicolumn{8}{|c|}{ Usuarios de Internet en los últimos 3 meses (75 y más años) } \\
\hline Total Personas & 1210017 & 43,8 & 59,3 & 24,0 & 78,9 & 45,5 & 56,6 \\
\hline Sexo: Hombre & 533405 & 54,3 & 57,9 & 21,2 & 77,8 & 52,7 & 66,9 \\
\hline Sexo: Mujer & 676612 & 35,5 & 60,4 & 26,1 & 79,7 & 39,9 & 48,5 \\
\hline Edad: De 75 a 84 años & 1022142 & 45,1 & 59,3 & 24,8 & 80,4 & 46,5 & 56,7 \\
\hline Edad: De 85 y más años & 187875 & 36,8 & 59,5 & 19,5 & 70,7 & 40,4 & 56,1 \\
\hline
\end{tabular}

Nota: Unidades de personas (75 años y más)

Fuente: Instituto Nacional de Estadística (2020). 
En la tabla 5 se muestran datos del uso de Internet en los últimos tres meses de la población de 75 años y más. Las actividades de comunicación (recibir o enviar correos electrónicos) las realizan el 54,3 \% los hombres y el 35,5 \% las mujeres; también, la misma actividad, en relación con la edad, de 75 a 84 años representa el 45,1 \%, y en mayores de 85 y más, el $36,8 \%$. En relación con telefonear o realizar videollamadas a través de Internet, los hombres representan el 57,9\%, mientras que las mujeres, el 60,4 \%; de 75 a 84 años, el 59,3\%, y de 85 años y más, el 59,5\%; más del $40 \%$ no puede telefonear o realizar videollamadas. $\mathrm{El} \mathrm{77,8 \%} \mathrm{de} \mathrm{los}$ hombres usa mensajería instantánea, mientras que las mujeres lo hacen en un 79,7\%. Con respecto al uso de Internet para leer noticias, periódicos y revistas diversas, ellos lo hacen en un $66,9 \%$, mientras que ellas, en un $48,5 \%$. En esta población, todavía un elevado número de personas no utiliza Internet para recibir o enviar correos electrónicos, telefonear o realizar videollamadas, mensajería instantánea, etc.

Realizadas las aportaciones cuantitativas, se ha puesto de relieve las diferentes organizaciones familiares de las personas de 60 años y más, por sexo, mostrando un elevado porcentaje de personas mayores viviendo solas, principalmente mujeres, por su mayor longevidad. Además, se han presentado datos del uso de Internet de la población de 75 años y más, por sexo y localidad de residencia, así como uso de Internet en los últimos tres meses de la población de 75 años y más. Seguidamente, se presentan las reflexiones de los adultos mayores de 60 años y más, para situar y contextualizar los datos presentados.

Antonio, de 67 años, reside en un pueblo cercano de Lleida con su esposa, y sostiene:

Nosotros hemos pasado estos meses tranquilos. Nuestra vida en el pueblo es tranquila y aquí todos nos conocemos. Todos nos conocemos y

Cuadernos de Filosofía Latinoamericana ISSN: 0120-8462 | e-ISSN: 2500-5375 | DOI: https://doi.org/10.15332/25005375 Vol. 42 N. ${ }^{\circ} 125$ | julio-diciembre de 2021 
en el pueblo hay mucha vida social. En el pueblo viven nuestros hijos y nietos y los vemos cada día. Durante el confinamiento y después, en el pueblo no hay tanto control como en las ciudades y aquí siempre hay más libertad. Más o menos hemos hecho la misma vida de siempre.

Solamente que este verano no hemos podido ir de vacaciones pero con todo lo que cae, iqué más da! (Entrevista realizada el 15 de enero de 2021).

El entrevistado explica sus vivencias durante el confinamiento y la posterior nueva normalidad y las restricciones a la vida social. Reside en un pueblo cercano a Lleida y considera que "hemos pasado estos meses tranquilos”. En el pueblo, los habitantes se conocen y tienen una vida social rica e intensa. Durante el periodo de limitación a la vida social "más o menos hemos hecho la misma vida que siempre", sostiene; en los pueblos no hay tanto control y han tenido igualmente interacciones sociales con familiares, amigos y allegados. El único inconveniente ha sido no hacer las vacaciones aunque lo relativiza por las especiales circunstancias vividas: “con todo lo que cae, iqué más da!”. La vida en los entornos rurales no ha sido tan restrictiva y limitada como en las ciudades con más densidad de población y más control social.

Teresa, de 72 años, residente en Lleida ciudad, viuda, afirma lo siguiente:

Yo vivo sola en mi casa de Lleida, en un barrio humilde, pero estoy bien. Aquí conozco a todo el mundo y nos ayudamos. Yo he pasado todos estos meses sola en mi casa y con poco contacto con las amigas y la familia. He salido poco de casa, solamente para comprar y algún paseo, pero como no se ha podido salir durante este tiempo, entonces no he salido. He mirado mucho la televisión e ir pasando. He tenido poca relación con mis amigas. Con mis hijos nos hemos llamado pero hemos estado meses sin vernos, iha sido triste, muy triste! Quizás lo más duro ha sido no ver a mis nietos, tienen ocho años, y he estado muchos meses sin verlos y ha 
sido muy duro. Había noches que soñaba con ellos, iimagínate!

(Entrevista realizada el 18 de diciembre de 2020).

La informante explica sus vivencias residiendo en Lleida ciudad; ella es viuda. En su barrio hay un sentimiento de solidaridad entre los vecinos: "aquí conozco y nos ayudamos"; seguramente, muchos vecinos residen desde hace años y se han construido sentimientos de empatía, solidaridad y ayuda mutua. Ella vive sola y ha pasado este periodo "sola en mi casa y con poco contacto con las amigas y la familia”. Salía de casa solamente para realizar gestiones necesarias, principalmente comprar. Muchas horas miraba la televisión, sin especificar ninguna otra actividad diferente; tal como lo explica, ha sentido hastío, aburrimiento y soledad. En estos meses no ha visto a sus hijos, "sin vernos", la situación "iha sido triste, muy triste!"; lo más desesperante ha sido no ver a sus nietos, "ha sido muy duro"; por las noches veía a sus nietos en sueños. Durante este periodo ha estado aislada y sola; y ha tenido pensamientos tristes y deprimentes.

Marta, de 85 años, residente en Barcelona, viuda, manifiesta:

Nosotras las viejas lo hemos pasado muy mal el año pasado, muy mal. Hemos estado abandonadas en casa y ni nos dejaban salir. Como si fuese pecado, no podíamos salir, todo aquello que era normal para nosotras estaba prohibido. Después el miedo, miedo a contaminarte, a ir a comprar, a hablar con las amigas... Era muy triste ver a gente conocida en la calle que se separaba guardando las distancias y se separaba para no estar cerca. Estos meses han sido muy solitarios. En mi caso, mi hermana se murió de COVID y también sé de amigas que se contagiaron y lo pasaron muy mal, alguna en la UVI y murió. Nosotras somos mayores y ya estamos muy solas, nadie nos hace caso pero en estos meses todavía ha sido peor. [La pasamos] muchas horas solas en casa, sin hacer nada, solamente mirar la televisión y nada más. Cuando estás en estas condiciones, la cabeza no para de pensar y ia veces piensa cosas feas! (Entrevista realizada el 10 de febrero de 2021). 
La entrevistada define la situación vivida durante la pandemia como "muy mal”. Se siente abandonada en su casa, sin poder salir; fue un castigo y seguramente peor el remedio que la enfermedad. El confinamiento les aseguraba no contagiarse, pero la vida en sus hogares fue claustrofóbica, deprimente y estresante: "todo aquello que era normal para nosotras estaba prohibido", asegura Marta. Destaca también el miedo, el suyo y de los vecinos; era muy triste ver a gente conocida del barrio separarse voluntariamente y evitar todo contacto social, "guardando las distancias y se separaban para no estar cerca". También conoce familiares y amigos que se contagiaron de la COVID-19, y su hermana murió. Aquellos meses fueron complejos de gestionar emocionalmente, estresantes, "muchas horas solas en casa, sin hacer nada, solamente mirar la televisión y nada más"; el aburrimiento y los pensamientos negativos "se ponen en la cabeza, la cabeza no para de pensar y ia veces piensa cosas feas!". Carlos, de 79 años, residente en Lleida, viudo, dice lo siguiente:

Yo soy profesor de universidad jubilado. Yo no soy muy sociable y ya tengo todas mis lecturas y proyectos para no aburrirme. La verdad que no he notado mucha diferencia entre mi vida antes de la pandemia y durante. Evidentemente todavía he realizado menos contactos sociales, pero yo ya estoy siempre muy conectado con el teléfono, WhatsApp, correo electrónico, videoconferencias... He tenido mucho trabajo y no me he aburrido durante estos meses. Mis hijos ya son mayores y no viven en España, están fuera, en el extranjero. Como te digo, como antes, muchas llamadas por teléfono y ahora las videollamadas... También te tengo que decir que mi casa es grande y tengo un patio donde estirar las piernas y andar un poco. En una habitación tengo una bici estática, en la cual estiro un poco las piernas, igual que durante estos meses de confinamiento. Creo que sobre todo la gente joven, adolescentes, y también las personas que necesitan más el contacto social lo han pasado peor que yo. (Entrevista realizada el 18 de enero de 2021). 
El entrevistado es profesor universitario jubilado y se define como "no muy sociable"; está en diferentes proyectos académicos y también lee y escribe, no se aburre. Su vida durante el confinamiento y la nueva normalidad no ha sido muy diferente a la de antes de la pandemia; tiene unas tareas diarias establecidas y una red de colaboradores de sus proyectos académicos. No tiene muchas relaciones sociales presenciales, aunque utiliza asiduamente dispositivos tecnológicos para comunicarse: videoconferencias, correo electrónico, mensajes, archivos, etc. Sus hijos son mayores, viven fuera de España, se comunican mediante diferentes dispositivos tecnológicos, igual que antes de la pandemia. En casa tiene una bicicleta estática y cuando quiere hace deporte, "estiro las piernas". Carlos no lo ha pasado mal estos meses, ha sido peor para los adolescentes, por sus especiales circunstancias vitales; aunque también para aquellas personas más sociables, aquellas que necesitan más el contacto presencial, cara a cara, ellos "lo han pasado peor que yo". María, de 86 años, reside en una localidad cercana de Barcelona, casada, vive con su esposo, y manifiesta lo siguiente:

Nosotros vivimos en un pueblo de costa, a unos 20 quilómetros de Barcelona. Es un pueblo [en el que] que todos nos conocemos. No poder salir es muy malo para nosotras. Estamos acostumbradas cada día a dar una vuelta por la playa y hablar con una u otra. Siempre hacemos lo mismo, siempre estamos en la calle y hablar. Estar tanto tiempo en casa sin poder salir ha sido muy duro, especialmente por mi marido. Él tiene dificultades para andar y necesita un cochecito eléctrico. Él ha estado todos estos meses sin salir de casa, solamente mirando la televisión y claro, el día se le hacía muy largo; había días que lo veía llorando y le preguntaba “¿qué te pasa?”, él no contestaba y después se le pasaba pero tampoco lo hablábamos. Alguna vez me decía que de esta no saldríamos, que aquello no lo podía resistir persona humana y que era muy duro. Yo intentaba consolarlo pero era muy duro para todos. Yo salía a comprar o

Cuadernos de Filosofía Latinoamericana ISSN: 0120-8462 | e-ISSN: 2500-5375 | DOI: https://doi.org/10.15332/25005375 
dar algún paseo con el perro, pero estar siempre en casa era como estar en la cárcel sin haber hecho nada. (Entrevista realizada el 20 de diciembre de 2020)

La entrevistada reside en un pueblo de costa, cerca de Barcelona, con su marido, quien tiene dificultades para andar y "necesita un cochecito eléctrico". La vida en los pueblos de mar es principalmente en la calle, con los vecinos, hablando de las cosas del pueblo, "hablando con una u otra". En estos pueblos el confinamiento y las restricciones a la vida social también ha sido difíciles de gestionar emocionalmente, por la intensa vida social de los pueblos de playa. Su marido no ha salido de casa estos meses y el día lo pasaba mirando la televisión. Algunas veces lloraba sin motivo aparente, “lo veía llorando y le preguntaba, ‘¿qué te pasa?’”, él no contestaba; deseaba ayudarle a superar el dolor y el sufrimiento. Algunas veces decía que "no saldríamos de aquello", no podía resistir ni "lo podía resistir persona humana".

Pedro, de 78 años, residente en Barcelona, casado, vive con su esposa, dice esto:

Durante aquellos meses que duró el confinamiento lo mejor fue la gente, como salíamos a las 8 de la noche a aplaudir a los médicos y enfermeros. De forma espontánea salíamos a la ventana y allí estábamos muchos aplaudiendo sin mucho sentido. Supongo que aquello fue muy raro pero era lo único que podíamos hacer, era lo único que nos dejaban hacer. Imagínate como eran las cosas que para los viejos la alegría de cada día era esperar a las 8 para poder salir y aplaudir y ver toda aquella gente haciendo lo mismo. Hacía mucha ilusión y reconfortaba mucho. Yo como estoy mejor que mi mujer, cuando no se podía salir, cada día por la mañana iba al garaje y me ponía a andar por el garaje. A veces también subía y bajaba escaleras de los pisos, del garaje hasta el quinto, subir y bajar; entonces daba una vuelta por el garaje y volver a subir. Entonces me cansaba y entonces aquello me reconfortaba. Por la mañana, ver a la 
gente andando en el balcón era una cosa muy rara, pero la gente hace cosas raras cuando está desesperada; en aquellos meses estábamos todos desesperados. (Entrevista realizada el 18 de enero de 2021).

El entrevistado explica que cada día salían a la ventana y aplaudían a los sanitarios: médicos, enfermeras. Aquel fue un hecho casual, social, que cristalizó en un momento concreto de la tarde-noche para agradecerles su esfuerzo, pero principalmente para encontrarse los vecinos y participar de un hecho social, una catarsis colectiva. Pedro explica que aquello era reconfortante: "hacía mucha ilusión y reconfortaba"; también daba un sentido al día, esperar a las 20 horas para salir al balcón, encontrarse con los vecinos, aplaudir y darse ánimos mutuamente. Por la mañana, el informante caminaba por las escaleras del edificio, "subía y bajaba escaleras, del garaje hasta el quinto, subir y bajar", se cansaba y también le reconfortaba emocionalmente. Destaca también la sorpresa de ver a los vecinos andar en el balcón, en un espacio tan pequeño, caminaban de lado a lado, "en aquellos meses estábamos desesperados”, sostiene. Asunción, de 70 años, reside en un pueblo cercano de Lleida ciudad, vive con su esposo, y manifiesta lo siguiente:

Nosotros somos una familia muy grande. En el pueblo estamos todos, hermanos, hermanas, hijos y nietos, y la verdad que siempre estamos muy acompañados. Somos una familia muy unida, mis hijas y sus maridos, con sus hijos, vienen casi cada día a casa, para vernos, para comer, para la ropa... Nosotros les ayudamos mucho y ellos todavía, siendo mayores, dependen mucho de nosotros. Durante el confinamiento y el verano, más o menos igual, mis hijas venían con sus hijos y allí estaban un rato. Salían a un descampado que tenemos delante y allí jugaban todos. Como somos una familia grande, todos juntos ya hacemos ambiente. Yo lo único que he sufrido ha sido por los niños de mis hijas, al no ir al colegio, cuando estaba cerrado, entonces pasaban todas las mañanas con nosotros y a veces terminaba agotada. Nosotros somos 
payeses y mi marido tiene tierra y al ser trabajo esencial entonces cada día iban a trabajar. Nosotros hemos continuado más o menos igual. (Entrevista realizada el 6 de noviembre de 2020).

La entrevistada explica su situación personal y familiar, así como las vivencias del confinamiento y la nueva normalidad. Su familia es "muy amplia” y en el pueblo están "todos, hermanos, hermanas, hijos y nietos y la verdad que siempre estamos muy acompañados”. Las relaciones entre todos son continuas, constantes, van a su casa diariamente, "para vernos, para comer, para la ropa...". Tal como lo explica, no hay diferencias significativas entre el confinamiento y antes, cuando no había restricciones a la vida social; fue "más o menos igual", continuaban teniendo relaciones presenciales con toda la familia; los niños jugaban juntos en un descampado y se entretenían. El cierre de las escuelas fue su principal limitación, ya que sus nietos estaban con ella y "terminaba agotada”. La ocupación familiar se consideró esencial, entonces sus hijos trabajaban con normalidad, "nosotros hemos continuado más o menos igual”.

Manuela, de 78 años, reside en Lleida ciudad, viuda, sostiene lo siguiente:

Vivo sola desde hace más de 30 años y tengo dos hijos. El grande vive muy cerca de mi casa, a dos minutos andando, y cada día iba a su casa, para ver como estaba, estar con él, hacerle compañía, ayudarle... Él se separó hace 10 años y todavía no lo ha superado y vive con su hijo, tiene 25 años. Ahora ve que el niño ya es mayor y ya piensa en independizarse y su padre está un poco triste. Entonces yo voy y les ayudo y les doy mi apoyo. Mi forma de comunicarme, con mis hermanas y mi otro hijo es con el teléfono, yo no tengo Internet y no sé cómo funciona. Todo esto ya me ha llegado tarde. Con el teléfono fijo tengo más que suficiente. Yo dentro de lo malo de este año no he estado tan mal, yo no sufro por mí, sufro por mis hijos y nietos. No sé cuándo acabará todo esto y después el 
trabajo. Al otro hijo mío le han hecho un $\mathrm{ERTE}^{2}$ y no sé cómo quedará, ¿y si no lo contratan y se queda en el paro? También da mucha pena toda aquella gente que está en las residencias, ellos dan mucha pena. Yo conozco a muchos y algunos que conozco se han muerto allí en la residencia. Sé que algunos se han muerto de pena, tantos días cerrados allí, sin su familia y sin ningún apoyo, me hace mucha pena. (Entrevista realizada el 6 de noviembre de 2020)

La informante reside en Lleida y es viuda. Tiene dos hijos; el mayor vive muy cerca de su casa y tiene una relación continua con él, "iba a su casa, para ver como estaba, estar con él, hacerle compañía, ayudar...”. Su hijo mayor se separó y todavía "no lo ha superado". Tal como lo explica, la entrevistada apoya y reconforta a su hijo: "entonces yo voy y les ayudo y les doy mi apoyo". Se comunica con sus hermanas con el teléfono fijo, como siempre, y no usa otros dispositivos tecnológicos, "no sé cómo funcionan, todo esto me ha llegado tarde", afirma. Durante estos meses, no lo ha pasado tan mal: "no he estado tan mal"; piensa principalmente por sus hijos y nietos, a nivel psicológico y económico. La pandemia ha creado mucha incertidumbre en la economía y muchas empresas han dejado de ser competitivas, dejando trabajadores en ERTE o sin trabajo. Además, las personas mayores de las residencias han sufrido más y han vivido situaciones más dramáticas y penosas, "sin su familia y sin ningún apoyo, me hace mucha pena", se lamenta.

Francisco de 85 años, residente de un pueblo cercano de Barcelona, vive con su esposa, y manifiesta lo siguiente:

\footnotetext{
${ }^{2}$ El Expediente de Regulación Temporal de Empleo, conocido como ERTE, es una medida de flexibilización laboral que habilita a la empresa para reducir o suspender los contratos de trabajo. Un ERTE es una suspensión con carácter temporal de los contratos. Por tanto, es un parón de la relación laboral entre empresa y empleado que se establece por un plazo determinado, aunque también se puede concretar en una reducción de la jornada.
} 
Mi hermano estaba en una residencia y se ha muerto allí. Hubo un brote de virus y hubo más de cinco fallecidos en la residencia. No nos dejaron ni entrar ni verlo y no hubo un entierro como debía de ser. Todo aquello fue muy triste, la familia llorando y no podíamos ni verlo ni despedirnos de él, iqué pena más grande! Toda la vida luchando para morir así, de esta manera, solo, sin nadie a tu lado ni nadie de tu familia. No entiendo cómo se pueden hacer las cosas así, iesto no es humano! Yo a nivel emocional todavía no lo he superado y mi mujer cada día llora, no sé si podremos superar todo esto que hemos vivido y quizás ya no nos queda fuerzas para luchar más. (Entrevista realizada el 6 de noviembre de 2020)

El entrevistado explica los últimos días de vida de su hermano, quien estaba internado en una residencia y murió allí. Aquellos días fueron tristes, no podían estar con él, acompañarle, darle consuelo y despedirse. Además, cuando murió, no pudieron realizar los rituales religiosos necesarios para canalizar el duelo y los vivos pudiesen integrar la pérdida, "todo aquello fue muy triste, la familia llorando y no podíamos ni verlo ni despedirnos de él”, declara. Aquello fue inhumano, emocionalmente todavía no lo han superado y su mujer llora por todo lo vivido; concluye su aportación diciendo que "ya no nos quedan fuerzas para luchar más". Antonia, de 82 años, residente de un pueblo cercano de Lleida, es viuda, y sostiene esto:

Te explicaré una cosa, nosotras somos ya viejas pero todavía nos queda mucho trabajo para realizar. Toda la familia todavía depende demasiado de nosotras. Mis hijos trabajan todo el día y sus parejas y todavía dependen de mí por las cosas de la casa. Cada día vienen a comer a casa, después se van a sus casas o a trabajar. Después mis nietos todavía van al colegio, ya que son pequeños y yo tengo que ir a buscarlos, darles de comer, estar con ellos y después volver a llevarlos al colegio. Por la tarde lo mismo, salen del colegio a les cuatro y media y muchos días los tengo 
que ir a buscar, darles de comer y estar con ellos, cuando sus padres no pueden que pasa mucho. Yo todavía no puedo morirme, ya que demasiadas personas dependen de mí. Tengo 82 años y todavía no tengo ni un día de descanso, vivo para mi familia. (Entrevista realizada el 6 de noviembre de 2020)

La entrevistada reside en un pueblo cercano de Lleida y es viuda. Tiene 82 años pero todavía "nos queda mucho trabajo para realizar", ya que su familia depende de su ayuda. Sus hijos trabajan todo el día y ella gestiona las tareas del hogar; además, cuida y educa a sus nietos, los lleva y recoge de la escuela. Todo el día está ocupada y, tal como dice, "yo todavía no puedo morirme, ya que demasiadas personas dependen de mí”. Explica que está totalmente entregada al cuidado de su familia. Durante el confinamiento y el periodo posterior de la nueva normalidad ayudó y cuidó a sus hijos y nietos: "no tengo ni un día de descanso", manifiesta.

Las aportaciones de las personas mayores resultan interesantes y valiosas por ser vividas en primera persona y por la proximidad de sus reflexiones y experiencias. Los contextos y las circunstancias de los informantes son variados y el grado de incertidumbre y desesperación también es diverso. En todo caso, algunos valoran las situaciones vividas desesperantes, estresantes y tristes, aunque de forma diversa por las situaciones, capacidades y competencias personales. El esposo de María tiene problemas de movilidad y necesita un coche eléctrico para desplazarse; para él ha sido agobiante no poder salir durante el confinamiento y la nueva normalidad. Por el contrario, Carlos ha tenido durante estos meses una vida similar a la vivida anteriormente; ha seguido con sus tareas y rutinas y utiliza los dispositivos tecnológicos de comunicación para seguir con sus proyectos académicos y relaciones personales. 


\section{Conclusiones}

El artículo ha pretendido mostrar una realidad social conocida por la ciudadanía española, principalmente por los adultos mayores, por ser vivida en primera persona. El virus aísla y profundiza el individualismo de las sociedades posmodernas. Principalmente, las personas se preocupan por su supervivencia (Han, 2020). En estas circunstancias, la democracia podría estar en peligro (Harari, 2020) y los gobiernos podrían implementar políticas eugenésicas, dejando a su suerte a los individuos más vulnerables (Zizek, 2020). La tercera edad conforma el colectivo de mayor impacto negativo por la pandemia (Vega et al., 2020).

Públicamente se han lanzado mensajes edadistas contra las personas mayores, reivindicando diferentes formas de exclusión social. Durante la pandemia se han priorizado estudios a colectivos con más futuro y socialmente más productivos, habiendo pocas investigaciones de las consecuencias de la pandemia en la vejez (Ayalon et al., 2020).

Se han presentado datos oficiales sobre las diferentes tipologías familiares de las personas mayores de 60 años; un elevado número viven solas o solamente con su cónyuge. Con 85 años o más, muchas viven solas, principalmente mujeres. Estas tienen más esperanza de vida y estos años están solas. En referencia al uso de Internet de las personas de 75 años y más, algunas lo han utilizado alguna vez, pocas, siendo algo marginal y poco significativo. Muchos no tienen los dispositivos tecnológicos ni las competencias digitales necesarias. En un periodo de confinamiento y de restricciones de la vida social, muchos solamente disponen de teléfono fijo, sin poder utilizar otros dispositivos tecnológicos. En la misma línea, la población de 75 años y más, sobre el uso de Internet (recibir o enviar correos electrónicos, videollamadas, mensajería, buscar información, leer noticias, participar en redes sociales, etc.), no lo utilizan; hay una brecha digital en las personas mayores. 
Las aportaciones de los entrevistados han resultado iluminadoras para comprender la variedad de contextos y situaciones vividas durante el confinamiento y la nueva normalidad. Antonio reside en un pueblo, en el que las personas han estado tranquilos; no hay tanto control social y han continuado con las interacciones sociales presenciales con familiares, amigos y allegados. Teresa vive en la ciudad, es viuda, y ha pasado estos meses sola en su casa; han sido unos meses tristes aunque lo más difícil emocionalmente ha sido no ver a sus nietos, pero ha soñado con ellos. Marta se ha sentido abandonada en casa y el remedio ha sido peor que la enfermedad; su hermana murió y algunos familiares y amigas se contagiaron, pero lo peor ha sido tantas horas sola en casa: "en estas condiciones la cabeza no para de pensar y ia veces piensa cosas feas!", manifiesta. Carlos tiene una vida ocupada, organizada y rutinaria y durante la pandemia ha seguido sus proyectos y lecturas académicas; además, tiene competencias digitales y las usa diariamente, no se ha sentido solo ni abandonado. Sus hijos viven en el extranjero y ha mantenido contacto con ellos mediante videollamadas, correos electrónicos.

María convive con su marido, quien tiene dificultades de movilidad y necesita un "cochecito eléctrico"; destaca principalmente su angustia y sufrimiento; él no ha salido de casa estos meses y lo veía llorando sin motivo aparente; interpretaba estar encerrado en casa como en una cárcel, sin haber cometido ningún delito. Pedro explica la desesperación colectiva y los encuentros de los vecinos cada día a las 20 horas en el balcón, lo que era una catarsis y subía los ánimos; para muchos, salir a las 20 horas en el balcón y poder aplaudir, hablar y decir frases reconfortantes era la acción más importante del día. Asunción vive cerca de su familia y están unidos; durante los meses de confinamiento sus nietos e hijas se encontraban en su casa y los niños jugaban juntos; para ellos fue "más o menos igual". 
Manuela está preocupada por sus hijos, pues uno está en ERTE y quizás se quede sin trabajo; hay mucha incertidumbre económica y muchas empresas no han podido adaptarse a la nueva coyuntura; la entrevistada recuerda a los internos de las residencias, quienes han estado meses solos, en la misma habitación, sin el contacto ni apoyo de su familia; también los fallecidos de las residencias de ancianos. Antonia explica que todavía es útil para su familia y no puede morirse, "tengo 82 años y todavía no tengo ni un día de descanso, vivo para mi familia”, sostiene.

Se han presentado las vivencias de los entrevistados durante el confinamiento y la posterior desescalada y limitación de la vida social. Hay una variedad de contextos y situaciones personales, por la localidad de residencia, familia, posibilidades económicas, competencias digitales, etc. En todo caso, destacan el sufrimiento y el estrés vivido, muchas veces, tal como dice Francisco, más allá de las capacidades humanas. El estudio ha pretendido describir diferentes vivencias y reflexiones de las personas mayores vividas y sentidas durante el confinamiento y la nueva normalidad, así como mostrar sus sentimientos, sufrimientos, preocupaciones y pensamientos vividos en estos tiempos inciertos.

\section{Referencias}

Albós, J., Martí, N., Mac Millan, A., Gerez. A., Estupiñá, G., y Sistac, H. (2020). El control en los tiempos del coronavirus. Perifèria: Revista de Investigación y Formación en Antropología, 25(2), 203-215. https://doi.org/10.5565/rev/periferia.799

Ander Egg, E. (2000). Métodos y técnicas de investigación social. Lumen.

Arias, C., y Polizzi, L. (2011). La amistad en la vejez. Funciones de apoyo y atributos del vínculo. Ponencia presentada en el III Congreso internacional de investigación y práctica profesional en psicología y XVIII Jornadas de investigación séptimo encuentro de investigadores en Psicología del Mercosur. Universidad de Buenos Aires, Argentina. https://www.aacademica.org/000-052/350 
Arruebarrena, A., y Sánchez, A. (2020). La soledad y el aislamiento social en las personas mayores. Studia Zamorensia, 19, 15-32.

http://revistas.uned.es/index.php/studiazamo/article/view/29363.

Ayalon, L., Chasteen, A., Diehl, M., Levy, B., Neupert, S., Rothermund, K., Tesch, C., y Wahl, H. (2020). Aging in times of the Covid-19 pandemic: avoiding ageism and fostering intergenerational solidarity. The Journals of Gerontology: Series B, 76(2), 49-52. https://doi.org/10.1093/geronb/gbaa051

Bermejo, J. (2016). La soledad de los mayores. Ars medica. Revista de Ciencias médicas, 13(3), 126-144. https://doi.org/10.11565/arsmed.v32i2.264

Cable, N., Bartley, M., Chandola, T., y Sacker, A. (2013). Friends are equally important to men and women, but family matters more for men's wellbeing. Journal of Epidemiology \& Community Health, 67, 166-171. http://doi.org/10.1136/jech2012-201113

Deusdad, B. (2020). COVID-19 and Care Homes and Nursing Homes Crisis in Spain: Ageism and Scarcity of Resources. RASP, 8(2), 142-168. https://doi.org/10.17583/rasp.2020.5598

Di Nola, A. (2007). La muerte derrotada. Antropología de la muerte y el duelo. Belacqva.

Fontana, L. (2020). Pandemia y rearticulación de las relaciones sociales. Perifèria. Revista de Recerca i Formació en Antropologia, 25(2), 101-114. https://doi.org/10.5565/rev/periferia.770

Fuentes, A., y Osorio, P. (2020). Una mirada a la vejez en tiempo de pandemia. Desde el enfoque de curso de vida y desigualdades. Revista Chilena de Salud Pública, Número Especial, 90-102. http://doi.org/10.5354/0719-5281.2020.60389

Gajardo, J. (2015). Vejez y soledad: implicancias a partir de la construcción de la noción de riesgo. Acta Bioethica, 21(2), 199-205. http://dx.doi.org/10.4067/S1726569X2015000200006

Galeano, M., Zuluaga, M., y Saldarriaga, G. (2020). Envejecimiento y Covid-19: los debates que impone el confinamiento. En A. Uribe-Tirado et al. (Eds.), Polifonía para pensar una pandemia (pp. 145-166). Universidad de Antioquia. https://www.researchgate.net/publication/346820867 Envejecimiento y Covid19-Los debates que impone el confinamiento de los mayores 
Golden, J., Conroy, M., Bruce, I., Denihan, A., Greene, E., Kirby, M., y Lawlor, A. (2009). Loneliness, social support networks, moods and wellbeing in community-dwelling elderly. International Journal of Geriatric Psychiatry, 24(7), 694-700. https://doi.org/10.1002/gps.2181

Han, B. (2020). La emergencia viral y el mundo de mañana. En Amadeo, P. (Ed.), Sopa de Wuhan. Pensamiento contemporáneo en tiempos de pandemias (pp. 97-113). Editorial ASPO.

Harari, Y. (05 de abril de 2020). La falta de solidaridad global y de liderazgo representa un peligro inmenso para la humanidad. (H. Alconada, Entrevistador). La Nación. https://www.lanacion.com.ar/el-mundo/yuval-noah-harari-la-falta-desolidaridad-global-y-de-liderazgo-representa-un-peligro-inmenso-para-lahumanidad-nid2350906/

Khan, S., Singer, B., y Vaughan, D. (2017). Molecular and physiological manifestations and measurement of aging in humans. Aging Cell, 16(4), 624-633. https://doi.org/10.1111/acel.12601

Klein, A. (2015). Del anciano al adulto mayor-procesos psicosociales, de salud mental, familiares y generacionales. Plaza y Valdez.

Klein, A. (2020). Los adultos mayores entre la "revolución" gerontológica y la "expiación" gerontológica. RASP, 8(2), 120-141. http://dx.doi.org/10.17583/rasp.2020.5408

Leturia, F., Yanguas, J., Arriola, E., y Uriarte, A. (2001). La valoración de las personas mayores: evaluar para conocer, conocer para intervenir. Manual práctico. Cáritas.

Parra-Rizo, M. (2020). Componentes de influencia más valorados en la calidad de vida por las personas mayores de 60 años físicamente activas. EJIHPE, 7(3), 135-144. https://doi.org/10.30552/ejihpe.v7i3.202

Quiroga, N. (2020). Coronavirus y economía: cuando el cuidado está en crisis. Pensar la pandemia. Observatorio Social del Coronavirus. CLACSO. https://www.clacso.org/coronavirus-y-economia-cuando-el-cuidado-esta-encrisis/ 
Ruiz Osorio, M. (2020). COVID-19 y muerte en la sociedad del espectáculo. En A. UribeTirado et al. (Eds.), Polifonía para pensar una pandemia (pp. 200-213). Universidad de Antioquia. http://bibliotecadigital.udea.edu.co/bitstream/10495/17635/4/UribeAlejandro 2 020_PolifoniaPensarPandemia.pdf

Santillán, C. (2020). El impacto psicológico de la pandemia de COVID-19 en México. Publicaciones de COMECSO. https://www.comecso.com/las-ciencias-sociales-y-elcoronavirus/impacto-psicologico-pandemia-mexico

Tahull, J. (2019). Centenarios. Entre la plenitud y la fragilidad existencial. Revista Internacional de Investigación en Ciencias Sociales, 15(2), 198-218. http://revistacientifica.uaa.edu.py/index.php/riics/article/view/828

Vega, J., Ruvalcaba, J., Hernández, I., Acuña, M., y López, L. (2020). La salud de las personas adultas mayores durante la pandemia de COVID-19. JONNPR, 5(7), 669765. https://doi.org/10.19230/jonnpr.3772

Waite, L., y Gallagher, M. (2000). The case for marriage: why married people are happier. Healthier and better off financially. Doubleday.

Zhang, J., Wu, X., Zhao, W., y Zhang, W. (2020). Recommended psychological crisis intervention response to the 2019 novel coronavirus pneumonia outbreak in China: a model of west China Hospital. Precision Clinical Medicine, 3(1), 3-8. https://doi.org/10.1093/pcmedi/pbaaoo6

Zizek, S. (2020). Pandemic! Covid-19 Shakes the world. OR Books. 


\section{Saint Merry-Hors-les-Murs : une aventure spirituelle inachevée à Paris}

[Debate]

Jean-François Petit ${ }^{*}$

Fecha de entrega: 30 de abril de 2021

Fecha de evaluación: 20 de mayo de 2021

Fecha de aprobación: 25 de mayo de 2021

Citar como:

Petit, J.-F. (2021). Saint Merry-Hors-les-Murs: une aventure spirituelle inachevée à Paris. Cuadernos de Filosofía Latinoamericana, 42(125).

https://doi.org/10.15332/25005375.6754

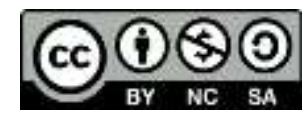

Le 28 février 2021, l'archevêque de Paris, Mgr Michel Aupetit, décidait soudainement de mettre fin au Centre pastoral St Merry (CPSM), plus connu sous le nom de Centre Pastoral Les Halles-Beaubourg. Créé en 1975 en plein cœur de Paris par un évêque courageux, Mgr Marty, il avait été confié à un prêtre audacieux, Xavier de Chalendar ${ }^{1}$, qui sut d'entrée de jeu s'entourer de laïcs compétents et formés théologiquement (Warnier, 1991).

Pendant plus de 40 ans, une grande métropole mondiale comme Paris aura donc eu un fleuron diocésain très actif dans le domaine culturel et artistique, l'innovation liturgique, l'accueil inconditionnel. Beaucoup de

\footnotetext{
* Maitre de conférences HDR en philosophie. EA 7304 Institut Catholique de Paris. ifpetit@netcourrier.com

${ }^{1}$ Petit, J.-F. (2019a). Xavier de Chalendar (1923-2015), un acteur majeur des transformations postconciliaires du croire à Paris. Dans : Coutel, C. ; Rota, O. (dir.), (2019). Se faire apôtre, du XIXe siècle à nos jours. Paris : Parole et Silence.
} 
réfugiés latino-américains, en particulier après le coup d'Etat militaire au Chili, en bénéficièrent. Dom Helder Camara y était comme chez lui. Il y a encore un peu de temps, pour ne donner que ces seules illustrations, on y discutait la vision de la résurrection de l'évêque anglican John Shelby Spong et de la question de la violence chez René Girard, des enjeux de l'encyclique Laudato Si et des moyens d'une solidarité concrète avec le territoire palestinien de Gaza.

Hélas, suite à des tensions récurrentes entre deux prêtres successifs et quelques laïcs de la communauté, qui ne surent pas faire la différence entre lutte contre le cléricalisme et leur refus personnel d'un clergé, Mgr Aupetit opta pour la solution abrupte de fermer le Centre pastoral, la paroisse territoriale minuscule sur lequel il était adossé restant, elle, ouverte.

« L'affaire » en serait peut-être restée là, sans l'émoi suscité à travers le monde par cette décision. Plus de 12 ooo personnes de plus de 54 pays protestèrent, ce qui montra à tous, si besoin en était, le rayonnement du Centre. Comment comprendre la situation ? Quels éléments de prospective donner? Ces deux questions seront les fils rouges de cette analyse.

\section{I/ L'analyse d'une situation ecclésiale devenue problématique}

Depuis le 28 février, l'émotion n'est pas totalement retombée, l'archevêque déclarant publiquement maladroitement dans une interview à la radio diocésaine s'être fait traité de « facho » par des membres de la communauté, au moment où il était interrogé sur une cérémonie traditionnaliste dans une église de la capitale où personne n'avait porté le masque anti-covid ${ }^{2}$.

\footnotetext{
${ }^{2}$ Cf. https://saintmerry-hors-les-murs.com/
} 
Au-delà de " l'événement St Merry », doit-on voir plus fondamentalement dans la fermeture du CPSM le signe de la fin d'une pastorale postconciliaire aux carrefours des enjeux du monde contemporain, ou du moins, d'un certain type de pastorale dans une grande ville urbaine comme Paris?

Pourtant, la décision du 28 février aura bien été une « rupture instauratrice », au sens que donnait le jésuite Michel de Certeau à cette expression (Petit, 2020): rupture, dans le sens où elle a obligé, en pleine pandémie, à faire le deuil d'un lieu, d'une façon de se rassembler, de se reconnaitre comme chrétien ; mais instauratrice, dans la mesure où elle a poussé à créer un nouvel espace, essentiellement digital pour l'instant, une configuration différente entre les membres de la communauté entre eux et avec leur environnement, des thématiques de recherche inédites, une façon neuve d'exprimer la foi.

En effet, après la période de trouble et de désarroi initial, il a fallu rapidement réinventer une façon d'être et de s'organiser. Plus que jamais, St Merry a pris la configuration d'une « nébuleuse », d’un "réseau », d'une « mouvance », même si une structure provisoire a rapidement vu le jour. Il s'agit en l'occurrence d'un « comité de pilotage », fruit de la fusion de membres de l'ancienne équipe pastorale, de responsables des pôles (art ; sacrements et formation, accueil, solidarité) de la communauté et de quelques membres cooptés. Cette structure, d'une quinzaine de personnes, s'est donnée comme tâche essentielle d'organiser et de représenter la communauté, qui, avant sa dissolution, était forte d'environ 300 membres, originaires de Paris et de sa proche banlieue pour la plupart, mais dont le rayonnement allait bien au-delà.

Sans rentrer d'entrée de jeu dans l'analyse des objectifs que Saint Merryhors-les-murs s'est donné, il faut d'abord dire qu'après le 28 février, le 
temps de Carême aura tout à fait été propice à vivre cette décision abrupte sous le mode spirituel de l'exil et de la distance prise vis-à-vis des formes conventionnelles et des lieux ordinaires de l'Église.

Comme prêtre membre de l'équipe pastorale, puis du comité de pilotage, j'ai donc été un acteur de ces passages délicats par l'abattement, la révolte et la reconstruction. Il serait donc particulièrement erroné de ne voir dans la fermeture de saint Merry que l'expression d'un combat d'un autre temps d'un évêque plutôt conservateur contre la mouvance progressiste de son diocèse. En réalité, l'expérience en cours de Saint-Merry-hors-les-murs est paradigmatique des recompositions sociales et culturelles à grande échelle dans les mégapoles, où le « croire sans appartenir », selon l'expression de la sociologue Grace Davie, devient l'une des formes dominantes des croyances religieuses, au moment même où l'appareil ecclésiastique tente de refaire surgir les formes plus conventionnelles d'attachement à la foi dans des lieux gentifriés de Paris.

Ainsi, le « bouillonnement » habituel de St Merry ne s'est pas arrêté au 28 février. Parmi les réalisations les plus significatives de Saint Merry-horsles-murs, une prière hebdomadaire à partir de la Parole de Dieu via internet, marqué par une dimension large de partage. Cette « horizontalité » montre la forte attente d'un ressourcement spirituel en toute liberté, dans une solidarité active et effectivement vécue.

En matière liturgique aussi, un autre groupe prie aussi régulièrement dans l'église même de saint Merry tous les dimanches, là justement où les célébrations eucharistiques ont été interdites par l'archevêque. Cette forme de résistance non-violente a pu connaitre un « répit » pour les Jours Saints où la chapelle d'un centre de rencontre chrétien, le Forum 104, et un paroisse - significativement située dans le quartier de la Bastille - ont accepté d'accueillir les célébrations de Saint-Merry-hors-les-Murs. Les 
Saint-Merriens, dont l'église avait été occupée deux fois par des collectifs de sans-papiers, ont redécouvert le sens de l'accueil des « migrants » qu'ils ont eux-mêmes beaucoup pratiqué par le passé.

Évidemment, même s'il ne s'agissait pas encore d'une « résurrection » de la communauté, Pâques aura pris tout son sens dans cette hospitalité eucharistique, contrainte aussi par le confinement : 50 personnes seulement dans le premier lieu, 80 dans le second, jauge sanitaire oblige ! Ainsi, de façon provocante, on pourrait presque dire que la décision choquante de l'archevêque de Paris a obligé la communauté à se refonder, dans un renouveau que plusieurs de ses membres appelaient en réalité de leurs vœux. En effet, des voix plaidaient pour une « pensée du dehors » de l'institution ecclésiale plus radicale, celle-ci semblant de plus en plus engluée dans les problèmes graves comme les abus sexuels ou des positions mal argumentées au plan éthique et surtout un manque d'attractivité lié à son incapacité à dire la foi en un langage renouvelé susceptible de parler à ses contemporains, notamment dans le domaine écologique.

Le bouleversement engendré par le choc du 28 février aura ainsi permis une interrogation sur le sens de l'aventure spirituelle dans les "périphéries existentielles » des grandes métropoles, le sens du risque pris, du dissensus, de l'engagement maintenu à la fidélité à une communauté. Peut-être que le sentiment de communion mystique avec les « témoins de Dieu » disséminés hors des institutions religieuses n'aura jamais été aussi grand, obligeant, par la force des choses, à se demander ce que voulait dire « croire ». La perte d'une tranquille assurance, sans partager le sort concret des marginalisés, des « migrants » dans la foi, ou plus généralement dans la vie, aura, de ce point de vue, été salutaire. 
Plusieurs saint-merryiens, formés à l'analyse des textes de De Certeau, auront ainsi su engager un travail d'introspection personnelle et de révision communautaire sur leur pratique de la foi, leur façon de vouloir chercher et dire le vrai ${ }^{3}$. Significativement, le thème des rencontres des groupes de Carême, avant même la dissolution, avait été « dans les incertitudes actuelles, comment rebondir ? ». Le choc de la pandémie, mais aussi les tensions dans la communauté, avaient déjà été l'amorce d'une prise de conscience. Celle-ci aura été finalement radicalisée par la crise vécue. On ne passe pas si facilement de la rupture au rebond.

Il faut bien reconnaitre que des formes de renouveau de l'expression liturgique peinaient à faire sens pour des personnes n'en ayant pas les clés. Et pourtant, quelle inventivité dans les nombreux commentaires de la Parole de Dieu par des laïcs, le bouleversement souvent approprié de l'ordre des textes liturgiques, la réécriture en des termes contemporains des prières eucharistiques et du credo, fruit par exemple de l'expression de foi des parents voulant faire baptiser leurs enfants, la qualité de l'ouverture et de l'envoi de la célébration, l'expression pénitentielle marquée tout au long de la célébration et non uniquement au début, l'absence de signe de croix à son entrée pour bien signifier le refus d'une rupture entre le profane et le sacré...

Mais, dans le même temps, quel dépit de voir les formes les plus conservatrices de la dévotion, notamment l'adoration du Saint Sacrement, retrouver un engouement, notamment auprès des jeunes chrétiens dans une grande métropole comme Paris, alors que des attentes spirituelles beaucoup plus variées restent très nombreuses et insatisfaites par les propositions pastorales ordinaires.

\footnotetext{
${ }^{3}$ Une présentation de cette recherche a eu lieu à Bogota en 2016 dans le cadre du partenariat entre les universités catholiques de Bogota et la faculté de philosophie de I'Institut Catholique de Paris.
} 
Une communauté comme celle de Saint Merry bâtie avec des prêtres sur les rivages de la recherche biblique (J. Pierron), des sciences humaines, notamment la psychanalyse (M. Bellet), la formation théologique (Xavier de Chalendar), la prise en compte des plus marginaux (G. Wybo) s'est de fait trouvé contestée par la curie diocésaine. Depuis 40 ans, l'énumération complète des groupes et instances nés ou fortement soutenus par st Merry échappe à toute comptabilité. Qui sait que les « restos du cœur ", l'association « les Morts de la rue », le Réseau chrétien immigrés, le Centre d'intelligence de la foi, les sessions de formation théologique de « l'Arc en Ciel » en sont en partie issus ?

Pendant des décennies, des expositions artistiques itinérantes conçues sur place ont irrigué les lieux ecclésiaux susceptibles de les accueillir en France et à l'étranger. Beaucoup d'agents pastoraux de France ou d'ailleurs, ont fait essaimer cette expérience, sans que Saint Merry revendique un quelconque « droit de propriété ». Peu se rappellent aujourd'hui aussi qu'une action résolue pendant la crise du SIDA a été menée à partir de Saint Merry, connu comme un lieu d'accueil des personnes homosexuelles les moins discriminants à Paris, que le cardinal Lustiger et son successeur le cardinal Vingt-Trois, les deux prédécesseurs de l'archevêque actuel, avaient eu la sagesse de ne pas entraver.

Par ailleurs, de grandes manifestations parisiennes, comme « la Nuit Blanche » ont permis à des milliers de personnes de participer à des performances artistiques dans un lieu qu'ils ne fréquentent jamais : une église. La réalité du dialogue interreligieux aura été prise au sérieux dans des « nuits sacrées » où différents groupes religieux ont pu être ensemble pour prier, conformément aux orientations des rencontres d'Assise voulues par le pape Jean-Paul II. Pour favoriser l'accès à la culture, des concerts gratuits de musique classique ont drainé deux fois par semaine 
bien des gens, faisant du lieu une « pépinière » de jeunes artistes talentueux.

Même chose dans les rendez-vous de l'art contemporain, saint Merry servant de « tremplin » à certains d'entre eux. Une programmation audacieuse en matière de musique contemporaine, non loin de l'IRCAM, l'Institut de recherche et coordination Acoustique/Musique, l'un des plus grands centres de recherche au monde se consacrant à la création musicale, avait trouvé sa place dans « l'écosystème » Saint Merry, avec d'autres manifestations culturelles, moyennant bien évidemment à chaque fois, une tentative d'évaluation de leur compatibilité avec le lieu, parfois problématique.

Encore récemment, le pasteur Lapsley, l'ancien aumônier de l'ANC d'Afrique du Sud, de passage à Paris, était émerveillé par le projet de cette « pastorale de l'art » capable d'annoncer de façon non conformiste l'Évangile, sans chercher la moindre récupération prosélyte. Une pastorale d'été généreuse, juste à côté de Beaubourg, avait aussi su conquérir de nombreux touristes.

En mettant provisoirement fin au Centre pastoral sans doute par peur mais surtout par grande méconnaissance de ce terrain d'évangélisation difficile, la hiérarchie catholique parisienne a surtout manifesté un écart de cette orientation pourtant souhaitée par le Concile Vatican II, promue au rang de priorité apostolique par Benoit XVI dans le souci de créer un « Parvis des Gentils », qui commençait en France à prendre sens. Tout se passe comme si les « clés de lecture » de ces " signes des temps » avaient été perdues, rendant ainsi les actions du Centre pastoral suspectes de subjectivisme, de réductionnisme vis-à-vis d'une présentation orthodoxe du mystère de la foi et surtout d'atteinte à l'intégrité des prêtres, 
même s'il n'est évidemment pas simple de gérer une communauté aussi tourbillonnante.

Dès lors, on peut se demander si Saint Merry-hors-les-murs n'est pas un peu en quête d'une voix perdue du christianisme, directement inspirée de la pratique des premières communautés chrétiennes, comme si cette altérité fondatrice était devenue inaccessible dans un pays de vieille chrétienté historique comme la France. Peut-on faire du neuf avec de l'ancien? seraiton tenté de demander à la manière de l'Évangile (Mt 9, 14-17) ?

Pour autant, le passage par la mort et la résurrection vécu le 28 février n'a-til pas décuplé, par le numérique, une plus que nécessaire fraternité en temps de pandémie ? Cette réorientation sous la contrainte n'a-t-elle pas finalement conduit à la réorganisation des priorités de la communauté, là encore, en une myriade de groupes, notamment ceux consacrés au débat ecclésiologique nécessaire dans la perspective du synode sur la synodalité ou celui sur l'avenir de la communauté mais aussi dans une communication plus réactive et plus ajustée via internet ou des modes de décision plus participatifs, dans un comité de pilotage large, plutôt qu'une équipe pastorale restreinte, où la coresponsabilité prêtre-laïc avait de plus en plus de mal à se vivre sereinement?

Plus que saint-Merry-hors-les-murs, n'est-ce ainsi pas toutes les « vieilles chrétientés » en proie à la désaffiliation, à l'individualisation du croire qui sont aujourd'hui dans un " entre-deux », entre un passé, certes, dans le cas présent, assez « glorieux », et un avenir assez incertain, dans la quête d'une audace pastorale et d'une légitimité nouvelle dans la proposition de la foi à destination de ceux peu enclins à vouloir y souscrire ?

Il est clair que ces débats étant souvent mal animés et mal arbitrés, des solutions aussi inappropriées que la fermeture du Centre pastoral ont pu être engendrées. Saint Merry se faisait fort de soutenir, au nom du respect 
des droits de l'homme, les chrétiens opprimés à travers le monde. La communauté portait notamment une attention soutenue à la créativité théologique née du synode sur l'Amazonie. Elle se recentre aujourd'hui en partie sur l'analyse de la violence dans la confrontation avec la pensée de René Girard, qui n’épargne pas, hélas, les relations ecclésiales. Indépendamment des modalités internes de gestion de ses formes de conflictualité, n'est-ce pas toute l'éthique du débat public qui est aujourd'hui en question? De ce point de vue, le fait qu'aux dernières élections présidentielles en 2017, dans un " échange de bons procédés » avec l'épiscopat français, la communauté de Saint Merry aie clairement appelé, au nom des valeurs chrétiennes à faire barrage à la candidate d'extrême droite, n'est sans doute pas un hasard. Mais qu'en sera-t-il l'année prochaine, alors que beaucoup d'électeurs ne veulent pas retomber dans la même alternative entre Emmanuel Macron, le président sortant, et à nouveau, la candidate d'extrême-droite ?

En son temps, conformément aux souhaits de l'épiscopat, Saint Merry a fait beaucoup pour réhabiliter la dignité de la politique en fournissant des éléments de discernement. Mais depuis l'affaire du « mariage pour tous », du nom de cette loi en 2012, qui aura ouvert le mariage aux couples de personnes de même sexe, la communauté de Saint Merry, malgré l'important travail d'un atelier « familles », est restée en tensions sur ce sujet. Ses propositions n'ont pas pu être ouvertement débattues dans un contexte français, où les religions sont de plus en plus marginalisées et suspectées de volonté de séparatisme, comme le montrent clairement les derniers projets de lois sur le sujet.

Malgré aussi la grande qualité de ses recherches pilotées par Mgr d'Ornellas, l'Église catholique en France n'arrive plus à se faire correctement entendre dans les débats éthiques marqués par un 
libéralisme extrême, comme dans le cas récent de la loi de dépénalisation de l'euthanasie ou de l'extension du délai de l'interruption volontaire de grossesse.

Depuis lors, le confinement n'a fait que conforter « l'archipélisation » de la France, c'est-à-dire, selon l'analyste politique Jérôme Fourquet, le renforcement de sa fragmentation, alors que justement Saint-Merry se proposait de se porter sur les « lignes de fractures de la société », en assez grande syntonie avec le souhait de Mgr Claverie, l'évêque dominicain d’Oran en Algérie, assassiné en 1996.

L'exculturation du catholicisme dans la société française et le repliement d'une partie de son épiscopat étant patent, les tentatives comme celle de Saint Merry de déplier ce que « le temps et les habitudes auront durci », pour reprendre l'expression de l'historien Alphonse Dupront, s'avèrent de plus en plus périlleuses.

De ce fait, une recherche ecclésiale libre, comme elle était ordinairement menée à Saint Merry, s'est trouvée peu encouragée, voire même contrecarrée. Le débordement constant de l'institué religieux, même dans un lieu assigné à une fonction de « laboratoire » comme Saint Merry, n'a plus rencontré au sein de la curie diocésaine une indifférence polie, à défaut d'une sympathie bienveillante. Il a été placé au cœur d'une contestation de ses formes de reliance, au sens originel du terme religare, à savoir relier et vivre des liens créés.

Ainsi, alors que le sol se dérobait sous les pieds de l'église diocésaine, notamment après le drame de l'incendie de la cathédrale Notre Dame de Paris, Saint Merry aura pu présenter pour certains le visage d'un boucémissaire parfait d'erreurs postconciliaires à rectifier, jugées notamment responsables de la dérive de l'autorité dans l'Église. En son temps, De Certeau constatait la difficile adéquation entre l'intérêt que portaient les 
chrétiens aux différentes expériences culturelles de son époque et leur volonté de retrouver ce qui inspiraient leur foi. La compréhension contemporaine de ces phénomènes supposerait plutôt l'élargissement d'un espace de pluralité et de liberté, dans des orientations mieux partagées. Il était de notoriété publique que la conception saint merrienne de l'art et du respect du travail des artistes, y compris dans leurs provocations et parfois leur morbidité, n'avait rien à voir avec la conception sacrale défendue au Collège des Bernardins, la faculté de théologie du diocèse de Paris créée par le Cardinal Lustiger. Mais n'est-ce pas l'articulation d'une critique artistique à une réflexion théologique qui, dans l'un et l'autre cas, a singulièrement fait défaut? Pour ce qui le concerne, l'exploration théologique de la seule œuvre contemporaine acquise par donation en 2015, le tableau du peintre russe Maxime Kantor Merry Cathedral est-elle suffisante, alors que ses Saint Thomas et Saint François et Saint Augustin sont en bonne place à l'Académie pontificale des sciences au Vatican ? Pour l'artiste accueilli en 2011 et 2012, il est clair que l'art ne peut être dissocié être dissocié du message joyeux et coloré des cathédrales médiévales mais aussi d'une présence aux côtés des exclus et de ceux qui veulent sortir d'un monde globalisé violent, en comptant notamment sur les ressources spirituelles?

C'est bien ce souci de penser ensemble les enjeux contemporains, en aidant à renouveler les approches de la foi qui reste au cœur de la démarche, à la fois dans la recherche d'objectivité d'un discours producteur de sens et de la trace de la structure constitutive de l'expérience chrétienne. Cette interrogativité pratique ne peut guère faire l'économie d'un refus d'un enfermement discursif sur les textes magistériels, les orientations reçues de l'institution sans que ne soient interrogées ses discours et ses fonctionnements. Mais la « porosité » de Saint Merry à la modernité s'est peut-être payée d'une inattention aux 
basculements ecclésiologiques néoconservateurs, aux singularités de la scène ecclésiale parisienne et aux médiations qui auraient permis de conserver des liens suffisants, sans avoir, en un langage redoutablement efficace de la communication diocésaine, à se faire qualifier de « dérive sectaire ».

Pour les adeptes du « temps long », l'analogie avec la crise de la paroisse Saint Séverin où un « comité de gestion » rassemblait en 1956 un prêtre et un laïc avant sa suppression complète en 1962 n'est pas sans faire sens. L'isolationnisme dangereux de Saint Merry, après la fin de la communauté Saint Bernard de Montparnasse qui restait dans Paris l'une des seules expériences postconciliaires, n'aura pas été compensé à temps par des alliance suffisantes pour éviter un étiquetage idéologique, alors qu'en réalité celui-ci était réducteur des tensions inhérentes à toute communauté paroissiale.

Par comparaison, les membres de saint Merry-hors-les-murs, dont certains se sont retrouvés isolés dans les paroisses ordinaires et d'autres proches des communautés protestantes, ont été amenés à vivre la foi sous les modalités d'une expérience plus intérieure et plus personnelle. Paradoxalement, de nouvelles énergies se sont libérées, comme si les membres étaient en train d'apprendre des situations et de s'apprendre mutuellement à faire face, ne serait-ce que pour sauvegarder par exemple les données électroniques de son site. Ce mouvement vers l'avant aura-t-il la capacité d'éroder les replis identitaires et de maintenir la volonté d'ouverture à l'altérité ? À la tendance lourde de la sécularisation, saint Merry-hors-les-murs entend répondre non par une surenchère réaffirmatrice de la foi mais bien une réflexion autour de la position de croyant dans une thématique d'accomplissement pascal, d'épanouissement et de libération individuelle et collective. 
En réalité, le travail sur une herméneutique de son passé confronté aux problématiques nouvelles nées d'une situation durable de confinement n'est pas encore totalement entrepris. La perspective du culturel et du théologique à l'ère bactériologique ne peut que prendre des contours inédits, en cherchant quelles pourraient être les possibilités d'insertion dans ces réalités inattendues. L’impossibilité de se fixer en un lieu territorial dans Paris relève temporairement d'une situation instructive des migrations de la foi et de la dimension pérégrinante de l'existence humaine. Pourtant, à bien y regarder, cette situation avait largement été anticipée par un atelier de " pastorale urbaine », selon son propre intitulé, dont le diagnostic, posé en 2019, se révèle, à postériori, prémonitoire de cette vulnérabilité d'ensemble.

\section{II/ Le cœur du problème : quelle annonce de l'Évangile dans la ville?}

Comment annoncer Jésus-Christ dans les grandes villes ? La « conversion de la pastorale » souhaitée par le pape François ne parait pouvoir être mise en place dans les mégapoles que par une sortie d'un ecclésiocentrisme de repli ou de refuge pour une conversion du regard : réfléchir à la pastorale urbaine suppose de partir non de la pastorale mais bien des transformations de l'urbain contemporain.

Dans son Texte d'orientation pastorale de 2015, la communauté de SaintMerry avait pris conscience du problème, en cherchant à promouvoir «L'Évangile dans la ville », tout en acceptant aussi de mieux penser « la ville dans l'église » de Saint-Merry4. Certes, il serait tentant de vouloir faire du lieu un havre de paix dans le centre hyperactif de Paris. Le bâtiment, en partie originaire de la Renaissance sur la base d'une église du IXe siècle,

\footnotetext{
${ }^{4}$ Cf. Texte d'orientation pastorale.
} 
plusieurs remanié et magnifiquement restauré, parle en lui-même mais le risque serait grand de ne valoriser que sa dimension patrimoniale exceptionnelle. Qui sait aujourd'hui que le poète italien Bocace et Saint Edmond, le futur archevêque de Canterbury, furent tous les deux paroissiens de Saint-Merry, un lieu qui inspira aussi le romancier Umberto Eco?

En fait, un écart s'était déjà établi entre la configuration du dimanche, très centrée sur la célébration de la paroisse et du CPSM et le reste de la semaine, marqué par une plus grande polyvalence entre activités cultuelles et culturelles. L'accueil des migrants, des touristes, des passants y était fortement valorisé. Mais le risque de ne former qu'une « communauté hors sol », décrochée de son environnement, aura été grandissant. Plusieurs membres de la communauté avaient conscience de tous les contacts furtifs liés à Saint Merry, en constatant qu'ils étaient capables d'engendrer une implication, certes ponctuelle mais durable, à la mesure de la diversité grandissante des raisons de fréquentation de tous les « chercheurs de sens » gravitant autour de la communauté.

Ainsi, sensible aux mutations de l'environnement autour de Saint-Merry, encouragé par Mgr Alexis Le Proux, l'un des deux vicaires généraux ayant démissionné depuis, un petit groupe animé par des prêtres et des laïcs s'était réuni six fois de décembre 2018 à juin 2019 pour envisager l'avenir à cinq ou dix ans de Saint-Merry. Il avait donné lieu à l'audition de personnes diverses, extérieures ou non à St Merry, chrétiens ou non, notamment un chercheur de l'IRI à Beaubourg, impliqué dans l'étude des sociabilités, et le président du conseil de quartier (revu après un colloque sur le futur arrondissement « Paris Centre »5), en parallèle à des contacts

\footnotetext{
${ }^{5}$ Colloque «Quels équilibres, Quels enjeux pour Paris Centre ? » du 30 mars 2019 organisé par la
} mairie de Paris. 
avec l'élue chargée du patrimoine, et le maire du $4^{\mathrm{e}}$ arrondissement de Paris, Ariel Weil. Ainsi il semblait opportun d'écouter ce que des acteurs de terrain du quartier, qu'ils soient politiques (au sens grec de polis), artistes, habitants du quartier, visiteurs ponctuels (jeunes, auditeurs ou intervenants occasionnels) pouvaient nous dire ou attendre de la communauté Saint-Merry pour promouvoir la vie en plein cœur de Paris.

La réflexion avait été menée sur un périmètre élargi aux églises SaintEustache, Saint-Leu, Saint-Merry), mais aussi pris en compte tout le doyenné et au-delà (les églises Saint Gervais, Bonne Nouvelle, Blancs Manteaux, au moment même où les touristes, après l'incendie de la cathédrale Notre-Dame commençaient à se reporter sur d'autres lieux comme notamment l'église Saint-Merry (surnommée non sans raisons « la petite Notre-Dame »).

L'attention avait délibérément été portée sur une pastorale qui puisse concerner largement toutes les personnes, celles qui passent, celles qui fréquentent le centre de Paris et pas seulement ses églises, pour mieux comprendre leurs modes de vie et écouter leurs aspirations multiples. Il semblait évident au groupe qu'il fallait même dépasser le concept de «paroisse d'élection » mieux prendre en compte une pastorale des "sensibilités » voire même une « pastorale des flux » dans l'hypercentre de Paris.

Cependant, les membres de cet atelier avaient estimé que réfléchir de façon large sur la place de ces églises supposait de ne pas être déconnecté des différentes fonctions (résidentielle, économique et commerciale, touristique, loisirs urbains) alors que, avant la pandémie, la surfréquentation de Paris-Centre semblait s'accentuer. 


\section{Une réinscription dans le périmètre urbain ? (Alain Genel)}

De ce point de vue, l'audition du président du conseil de quartier SaintMerry, Alain Genel, fut instructive. A partir du conseil de quartier et surtout de l'association « Aux 4 coins du $4^{\mathrm{e}}$ », son point de vue était d'inviter les Saint Merriens à s'intéresser vraiment à tout ce qui bouge dans le quartier, en ayant les bons « capteurs », par exemple les « ateliers citoyens » à partir d'un réseau d'adhérents motivés.

Il lui semblait important que la réflexion sur l'avenir de Saint Merry tienne compte du projet de démocratie participative mené localement, notamment sur des thématiques concrètes comme l'environnement, la scolarisation, le tourisme de proximité, mais non déliées de prises en compte plus larges, notamment pour Paris-Centre l'avenir de l'île de la Cité, en faisant préciser les attentes des habitants, malgré dans le cas précis le gigantisme des projets en cours tels que le déménagement du Palais de Justice, le réaménagement de l'hôpital de l'Hôtel-Dieu, la création d'un espace de logements au sein d'un ensemble plus vaste à imaginer.

Alain Genel donna de ce point de vue des informations précieuses : le quatrième arrondissement, sur lequel se situe l'église Saint Merry aura en fait passé de $4 \%$ à $14 \%$ de logements sociaux, soit environ 2000 logements pour l'arrondissement. Le projet Morland entendait encore augmenter ce nombre, tout en ménageant des commerces au rez-dechaussée, avec 300 logements supplémentaires dont 100 logements sociaux.

Le passage de quatre arrondissements à un seul « Paris centre », effectif depuis 2019, représentait selon lui une occasion pour améliorer la gestion de la vie, même si dans les faits, cette mutation se sera surtout traduite par une redistribution et une prise de contrôle des services administratifs des 
anciens arrondissements. Il voyait déjà se dessiner ce qui pourrait devenir ce nouveau Paris Centre, formé de 25000 habitants, bordé d'un côté par la Seine, de l'autre allant jusqu'au boulevard Etienne Marcel, voire la rue Réaumur : un lieu marqué par des flux engendrés par des grands commerces et des équipements culturels comme le Centre Pompidou (puis la fondation Pineau), dans lequel les églises auraient à trouver une nouvelle place.

\section{Des retrouvailles avec le Centre Pompidou ? (Vincent Puig)}

Dès lors, il aura été intéressant de voir comment se positionnait Vincent Puig de l'Institut de Recherche et d'innovation (IRI) fondé par Bernard Stiegler et basé justement au Centre Pompidou. A ses débuts, celui-ci avait mis en place des correspondants locaux, sensés participer à sa vie et favoriser son implantation. Mais ce système fut peu à peu remplacé par les « cartes-privilège ». L'esprit de participation aura été remplacé par une massification extrême.

De son intervention, il ressortit qu'un projet pastoral ne pouvait pas être délié d'une réflexion sur le suivi du changement culturel et scientifique où le calcul est désormais largement préféré à la recherche de causalité mais aussi une interrogation sur les formes d'associations contributives (le développement des sciences participatives, l'observation des pratiques amateurs, de la diversité et des groupes) et les modes de socialité (Petit, Puig, Laquais, 2019b). Vincent Puig demandait d'être particulièrement attentif aux dynamiques de production des savoirs créés à partir de pratiques participatives, que ce soit autour de propositions concrètes en matière économique, éducative ou sociale.

De façon plus générale, Vincent Puig constatait une disjonction entre travail (de plus en plus dans des data centers) et habitation - cette vie 
« hors-sol » provoquant aussi souffrance et violence, les personnes manquant notamment d'ancrage territorial, des institutions culturelles comme le Centre Pompidou, centré sur un modèle de consommation et toujours avec le même public, ne compensant en réalité guère ce manque.

Ainsi, il vaudrait mieux se concentrer aujourd'hui, en terme d'attention sur les « pratiquants », du vélo, de la cuisine de rue bio, du jeu, tournoi d'échec... que sur les « publics » ciblés par les formes de marketing culturel, pour mieux appréhender ce que les personnes désirent réellement faire ensemble.

Selon Vincent Puig, l'IRCAM, l'une des institutions à proximité de Saint Merry, pendant un temps, aura vécu une expérience très parallèle à celle de Pompidou, à savoir la constitution d'une « tour d'ivoire » autour de son fondateur, le musicien Pierre Boulez. Mais désormais d'autres pratiques ont pu naitre, comme le club d'informatique musicale, qui a pu créer un forum où 5000 personnes s'y rattachent. Celui-ci se trouve aujourd'hui compléter par des espaces de rencontres, « les ateliers de l'IRCAM » ciblés sur la musique digitale Dans le cas présent, l'enjeu parait avoir été la constitution d'une vraie communauté, tournée vers des amateurs, dans des techniques et sociabilités partagées.

Dès lors, cette figure de l'amateur parait essentielle. Pour « faire ensemble », il s'agit souvent de démarrer de façon très modeste par des rencontres, des ateliers, autour d'un « faire ». Une « communauté d'amateurs » permet d'éviter un fonctionnement « hors-sol », accentué par les institutions culturelles marquée par le gigantisme, l'anonymat et la consommation. Ainsi, la détermination d'un projet pastoral ne peut faire l'économie d'une sensibilité à ces « signaux faibles », que constituent la cristallisation les projets d'activités, parfois très éphémères, une question 
qui se pose en réalité désormais aussi bien dans les musées, les bâtiments publics que les églises depuis l'épidémie.

Plus largement, face à la tentation d'une recentralisation, qui en réalité, marque ses limites, il vaudrait mieux, selon Vincent Puig, chercher un changement de modèle. De ce point les réflexions et actions_autour de la réintroduction de l'artisanat, de l'industrie, de l'activité agricole, dans le tissu urbain devraient être regardées de près, autant que la multiplication des start-ups et du co-working dans le quartier. Le processus « Église verte » aurait pu être une réponse pour Saint Merry.

En définitive, le lien avec le Centre Pompidou ne serait-il pas à recréer ? A ses origines, le Centre Beaubourg avait un lien avec l'école Saint-Merry mais s'en est coupé pour passer dans un modèle industriel, chaque activité devenant ultra-spécialisée. N’y aurait-il pas lieu de recréer de l'horizontalité dans les relations, d'accueillir plus les propositions du Centre Pompidou le temps de ses travaux (2024-2027), tout en accompagnant cette période de conférences sur ses transformations ? Vincent Puig laissa ces questions ouvertes. Il était important de les croiser avec celle de Laurent Bellin, l'animateur de l'accueil musical de Saint Merry.

\section{Se tourner vers les plus jeunes ? (Laurent Bellin)}

Dans son audition au groupe " pastorale urbaine », Laurent Bellin rappela que l'idée de départ de l'accueil musical du samedi soir et du dimanche après-midi était de proposer une tribune à de jeunes musiciens, alors que peu d'associations le faisaient dans Paris naguère. L'équipe pastorale de Saint Merry avait souhaité professionnaliser cet accueil en embauchant deux résidents responsables de la programmation (contre l'attribution d'un logement sur place). L'accueil musical aura de fait été orienté par la 
musique classique et contemporaine sur la base d'une entrée libre. Pour ce qui les concerne, les Rendez-Vous Contemporains (RVC) auront par la suite été dédiés à la musique expérimentale sur la base d'entrées payantes. Alors que l'Accueil musical constatait un renouvellement progressif du public, les RVC attiraient un nouveau public, sans que les choix de ces derniers soient toujours clairement assumés par l'ensemble de l'équipe pastorale.

Pour autant, il paraissait intéressant à Laurent Bellin de réfléchir à cette culture évènementielle_qui semble marquer les « adulescents » (les 30/40 ans entre l'adolescence prolongée et l'âge adulte). Ceux-ci lui semblent ne plus être vraiment attachés à un lieu ou à des formes de continuité. Ils apparaissent nomades, vont voir un peu partout notamment dans les réseaux sociaux qui présentent des aspects communautaires. Ils fréquentent les magasins plus pour discuter que pour acheter. Ils semblent déracinés, mais ils demandent des systèmes de valeurs. Si la Pop culture est mainstream pour eux, en façonnant un mode de pensée, elle s'articule aussi à des formes de communautés non-territoriales (autour de la science-fiction, de courants postapocalyptiques, du cyberpunk, du rétrofuturisme...)

Face à ces évolutions, Laurent Bellin estimait, non sans raisons, que la communauté de St Merry était un peu restée « dans son monde », dans un « entre soi », en se croyant révolutionnaire mais en réalité en demeurant figée dans ses codes, dans une forme élective ressemblant de fait à une paroisse. Or des éléments de sa culture évènementielle comme la « Nuit sacrée » auraient dû être exportés ailleurs qu'à St Merry comme dans une mosquée, une synagogue ou un lieu différent d'une église.

Bien évidemment, il aurait été bon de tirer de chacun de ces entretiens des problématiques et des stratégies pastorales. Ces orientations pouvaient- 
elles aussi servir de socle à un projet de refondation dans une conception de l'annonce de l'Évangile qui ne soit pas unidirectionnelle des instances de l’Église vers les tous les autres ? Le défi reste entier. Hélas, la crise vécue par Saint Merry n'a pas permis à ces réflexions prospectives de déboucher. Il est clair qu'elles auraient pû commencer par être combinées avec celles sur la « ville créative ». Il ne s'agissait donc pas seulement de commencer par travailler sur les alliances à opérer au sein du maillage territorial ecclésial ou de « cibler » quelques publics privilégiés, mais bien d'analyser les transformations de fond des pratiques dans les hypercentres urbains comme celui de Paris.

Certes, dans l'environnement immédiat de Saint-Merry, il est indiscutable qu'un axe à dominante culturelle, allant de la Fondation Pineau au Centre Pompidou, va se renforcer. L'Église risque d'en être absente. Mais en réalité, les changements urbains à prendre en compte pour Paris sont beaucoup plus nombreux : le souci de l'usage et de la mixité des espaces dans la métropole, son réaménagement dans la perspective des Jeux Olympiques et de l'Exposition universelle, les évolutions nécessaires liées notamment au changement climatique ou au développement de la révolution numérique et de l'intelligence artificielle.

Pour l'heure, la communauté Saint-Merry-hors-les-murs est devenue, par la force des choses, adepte d'un nomadisme religieux. Elle est le signe d'un christianisme urbain parisien éclaté, acculé à un risque de dissémination total alors que le temps des tâches propres aux chrétiens est loin d'être terminé. Se défaire d'un mode de croire et de savoir pour apprendre à voir et à écouter, sans se focaliser sur des points de crispation ou des représentations périmées n'est pas chose aisée. L'expérience du Centre pastoral Les Halles Beaubourg ne devait-elle pas mourir pour que d'autres attestations lui succèdent et qu'un surcroit d'agir au nom de l'Évangile, aux marges de l'Église, prenne le relais ? La question reste entière. 
Le 30 avril 2021

\section{Bibliographie}

Petit, J.-F. (2020). Michel Foucault et Michel de Certeau, le dialogue inachevé. Paris : Parole et silence.

Petit, J.-F. (2019a). Xavier de Chalendar (1923-2015), un acteur majueru des transformations postconciliaires du croire à Paris. Dans : Coutel, C. ; Rota, O. (dir.), (2019). Se faire apôtre, du XIXe siècle à nos jours. Paris : Parole et Silence.

Petit, J.-F ; Puig, V. et Laquais, V. (dir.). (2019b). Boites noires et gilets jaunes : regards croisés sur la socialité à l'ère de l'anthropocène. L'Harmattan.

Warnier, P. (1991). Saint-Merri: nouveaux visages d'Eglise. Préface de Xavier de Chalendar. DDB Christianis. Paris : Zodiaque Editions. 